\title{
Sustainability of postabortion care in Peru
}

Janie Benson

Victor Huapaya

Follow this and additional works at: https://knowledgecommons.popcouncil.org/departments_sbsr-rh

Part of the Demography, Population, and Ecology Commons, International Public Health Commons, Public Health Education and Promotion Commons, and the Women's Health Commons How does access to this work benefit you? Let us know!

\section{Recommended Citation}

Benson, Janie and Victor Huapaya. 2002. "Sustainability of postabortion care in Peru," FRONTIERS Final Report. Washington, DC: Population Council. 


\title{
Sustainability of Postabortion Care in Peru
}

\author{
Janie Benson \\ Vice President, Research and Evaluation \\ Ipas \\ Víctor Huapaya \\ Training and Service Delivery Associate \\ Ipas
}

May 2002
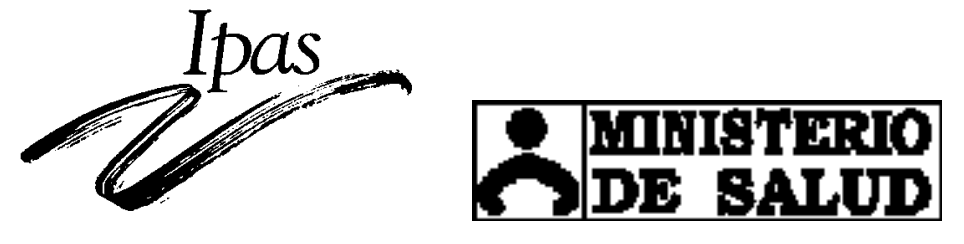

(1) Population Council
7 Frontiers

This study was funded by the U.S. AGENCY FOR INTERNATIONAL DEVELOPMENT (USAID) under the terms of Cooperative Agreement Number HRNA-00-98-00012-00 and Population Council subagreement Number AI100.78A. The opinions expressed herein are those of the authors and do not necessarily reflect the view of USAID. 


\section{SUMMARY}

Complications of unsafely-performed abortions remain an important contributor to maternal mortality in Peru. Emergency treatment of abortion complications has long been provided by facilities of the national Ministry of Health (MINSA). However, quality of care is poor and services are usually confined to hospitals, limiting access by women residing in remote areas of the country. From 1996-98, MINSA, Ipas and the Population Council conducted a study at Hospital Nacional Daniel Alcides Carrión, a tertiary-level hospital located in metropolitan Lima. The study assessed the effectiveness of a postabortion care (PAC) training and service delivery intervention comprised of the following components:

- Initial and refresher training of hospital staff involved in PAC service delivery;

- Improvements in clinical care, including a switch from sharp curettage (SC) to manual vacuum aspiration (MVA) for treatment of incomplete abortion;

- Provision of postabortion contraceptive information and delivery of methods;

- Provision of medical care information to patients; and

- Reorganization of PAC services from an inpatient procedure, requiring hospitalization, to an outpatient service provided in the obstetricsgynecology emergency room.

The study described in this report is a follow-up to the original research conducted at Hospital Carrión in 1996-98. The goal of the present study, carried out from 2000-02, was to determine the sustainability of the PAC intervention introduced in the hospital and the extent to which the outcomes of the intervention have continued. Hospital Carrión has provided PAC services without external technical or financial assistance for postabortion care since the conclusion of the original study. The present study is the first known research to examine how well a PAC intervention and resulting improvements have been maintained over the long term.

The objectives of the study were to assess changes over time in the following outcomes: the use of MVA for incomplete abortion; provision of family planning information to postabortion patients; acceptance of contraception by postabortion patients prior to discharge; provision of medical care information to patients; length of hospital stay and resources used by the hospital and patients for PAC services. An additional research objective was to describe the organizational and environmental contexts that influenced changes in the PAC outcomes.

The original study utilized a pre-post intervention design with no control group. Preintervention data (stage 1) were collected in 1996 for the outcomes listed above. Following implementation of the PAC intervention, post-intervention data were obtained in 1997 to measure changes in these results (stage 2). The present study consisted of a 
third, follow-up stage of data collection to document the long-term continuation of outcomes (stage 3). Data collection included review of the surgical logbook, patient exit interviews $(n=119)$, completion of a clinical history form, a time-motion study to observe PAC patients from arrival at the emergency room until departure $(n=18)$, a supplies and equipment inventory, and individual, qualitative interviews with providers and policymakers $(\mathrm{n}=13)$.

The findings indicate that the PAC services and related outcomes have been well sustained over the three-year period since the conclusion of the original study. All of the sustainability indicators were met and, in most instances, surpassed. In the year 2000, for example, $99 \%$ of clinically-appropriate PAC patients were treated with MVA. For postabortion family planning, more women in stage 3 than in stage 2 reported being informed about the risk of an immediate pregnancy, receiving family planning information and leaving the hospital with a contraceptive method. While the delivery of medical care information remained low, in stage 3, there was some improvement over the drops suffered between stages 1 and 2. The average length of stay and related costs in stage 2 were also maintained in stage 3. Several areas of PAC services merit additional attention for desired improvements, including the provision of more comprehensive medical care information, changes in pain management practices, especially prior to and after the evacuation procedure, and increased personnel time spent in direct contact with PAC patients.

A major factor that contributed to the sustainability of PAC outcomes included strong political leadership both within and outside the hospital. The selection of both current and future PAC providers and trainers in the original training courses, the rapid uptake of the MVA technique by resident physicians, the wide range of responsibilities and skills of the obstetrices (professional midwives) who offer counseling and contraceptive methods, and the institutionalization of training by more experienced providers to those with less experience has supported the continuation of the PAC services. The new ob-gyn emergency room where outpatient services are offered has also facilitated the institutionalization of services and improved the efficiency of patient management. The overall availability of supplies, equipment and sufficient personnel has also helped the delivery of PAC. Areas still in need of improvement are procedures related to collection of patient fees, gaps in some supplies and equipment, and the lack of written clinical protocols.

The lessons learned from the long-term experience of Hospital Carrión will continue to benefit PAC services. This model of sustainable, high-quality care has the potential for broad application in countries throughout the region. With minimal resource investment and strong political leadership, postabortion care can truly become accessible to women in Peru and the rest of Latin America. 


\section{CONTENTS}

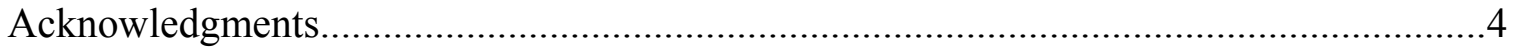

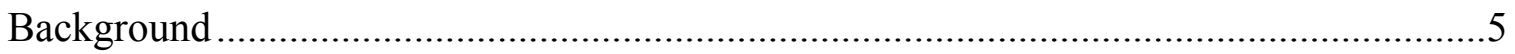

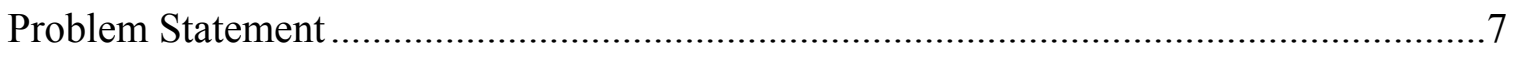

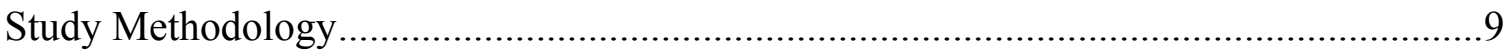

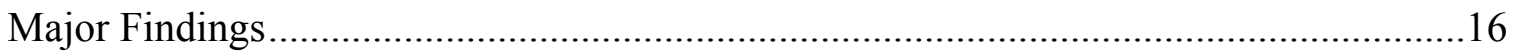

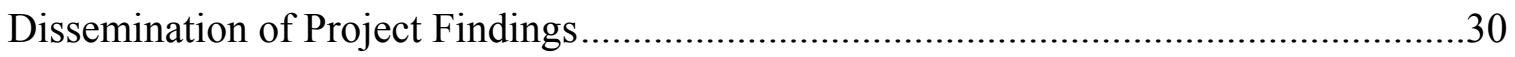

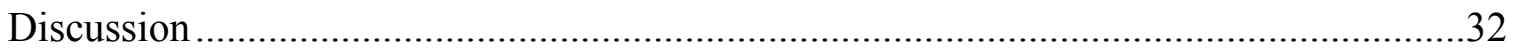

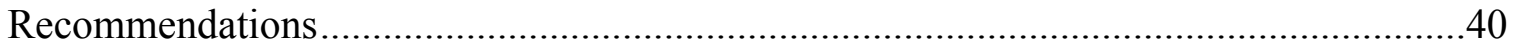

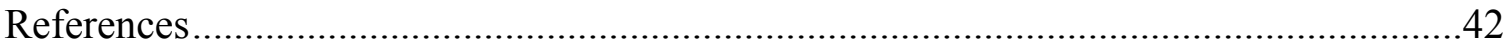

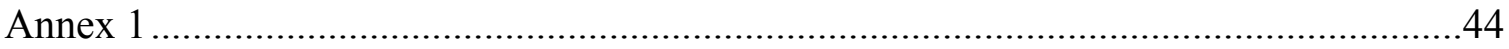




\section{ACKNOWLEDGMENTS}

The individuals listed below contributed immeasurably to the implementation and dissemination of the study. In particular, this research would not have been possible without the enthusiastic support of the staff of Hospital Nacional Daniel Alcides Carrión. A special note of appreciation goes to the data collection team and supervisor, Dra. Luisa Hidalgo. We also wish to thank the patients, providers and policymakers for their willingness to share their time and perspectives with us. Additional support for this project was provided by the World Bank.

Ministerio de Salud (MINSA)

Dr. Jorge Parra, Director, Social Programs (1998-2001)

Dr. Alfredo Guzmán, Advisor to the Minister of Health (2000-01)

Hospital Nacional Daniel Alcides Carrión

Dra. Luz Juárez, Executive Director (1995-2001)

Dr. Julio Aguilar, Director of Family Planning Services

Dr. Emilio Blanco, Executive Director

Dr. Jorge Alcántara, Chief, Department of Obstetrics-Gynecology

\section{Data Collection Team}

Dra. Luisa Hidalgo, Field Supervisor

Fabiola Carpio

Ruth Bonilla

Jeannette Castillo

Carmen Ortíz

Julissa Atencio

Rosanna Solf

Tatiana Merejildo

María Elena Planas (key informant interviewer)

Elizabeth Aliaga (key informant interviewer)

The Population Council (FRONTIERS Program)

Celeste Marin

Joanne Gleason

Dr. John Townsend

Ipas

Dr. Alvaro Gaillour

Carmen Guzmán

Virginia Chambers

Amanda Martínez

Anne Corbett

Maribel Mañibo

Suchitra Dutta

Jennifer Smith

Judith Gale

Dr. Barbara Crane 


\section{BACKGROUND}

\section{Unsafe Abortion and Postabortion Care in Peru}

Recent estimates of maternal mortality in Peru have shown a decline from 265 to 185 deaths per 100,000 live births (1996 and 2000 Demographic and Health Surveys) (Instituto Nacional de Estadística e Informática, et al., 2001). While improved sampling and estimation techniques likely account for some of the decrease, the magnitude of the change indicates progress in achieving reductions in this important public health indicator. The maternal mortality ratio for Peru, however, remains high by Latin American standards, with complications from unsafely-performed abortions comprising a large proportion of maternal deaths.

The Peruvian abortion law is highly restrictive, permitting legal abortion only to save the life of the woman or to "prevent serious damage to her health" (CLADEM, et al., 1998). Nevertheless, Peru has one of the highest estimated abortion rates in Latin America, 51.8 per 1000 women of reproductive age (Singh and Wulf, 1994). This rate is largely attributable to the recent rapid fertility decline and still-high use of traditional contraceptive methods (Instituto Nacional de Estadística e Informática, et al., 2001; Singh and Wulf, 1994). Women seeking to end an unwanted or unplanned pregnancy often turn to untrained providers working in unhygienic conditions for their procedures.

Complications from clandestinely induced abortions and miscarriages in Peru lead to just over 72,000 hospitalizations annually (Singh and Wulf, 1994). Recent reports and forthcoming research by Peruvian investigator, Delicia Ferrando, indicate that the quality of induced abortion services overall in Peru has improved in the last decade, resulting in fewer cases of complications seen in public hospitals (Benson and Huapaya, 2002).

Emergency treatment of abortion complications has long been provided by facilities of the national Ministry of Health (MINSA). However, the quality of care is poor and services are usually confined to hospitals, limiting access for women residing in remote areas of the country. In recent years, MINSA and several international non-governmental organizations (NGOs) have collaborated to improve the delivery of postabortion care (PAC) services ${ }^{1}$ in Peru.

From 1996-98, MINSA, Ipas and the Population Council conducted a study at Hospital Nacional Daniel Alcides Carrión, a tertiary-level hospital located in metropolitan Lima, entitled, "An Operations Research Project to Test an Integrated, Hospital-Based Model of Treatment for Abortion Complications and Delivery of Family Planning in Peru" (Benson, et al., 1998). The study assessed the effectiveness of a PAC training and service delivery intervention comprised of the following components:

\footnotetext{
${ }^{1}$ Postabortion care (PAC) consists of three components: emergency treatment of complications of spontaneous or induced abortion; postabortion family planning counseling and services; and linkages to other reproductive health care (Greenslade et al., 1994). Adoption of integrated PAC in health care facilities is increasingly recognized as a feasible, direct strategy to reduce the negative consequences of unsafe abortion.
} 
- Initial and refresher training of hospital staff involved in the delivery of PAC services;

- Improvements in clinical care, including a switch from sharp curettage (SC) to manual vacuum aspiration (MVA) ${ }^{2}$ for treatment of incomplete abortion;

- Provision of postabortion contraceptive information and delivery of methods;

- Provision of medical care information to patients; and

- Re-organization of PAC services from an inpatient procedure, requiring hospitalization, to an outpatient service provided in the obstetrics-gynecology emergency room.

Using pre- and post-intervention measures, the changes in PAC services resulted in improvements in a number of outcomes: increased use of MVA; improved provision of family planning information; increased acceptance of contraceptive methods prior to hospital discharge; reduced length of patient stay; and decreased costs of care to the hospital.

Using the Hospital Carrión services as a model, from 2000-02, the department (state) Ministry of Health of Ayacucho and Ipas have upgraded the postabortion care offered in hospitals and health centers, improving quality and increasing access by women in this largely rural, mountainous region. Furthermore, beginning in 1996, MINSA and Pathfinder International/Peru collaborated to improve PAC services in over 40 hospitals throughout the country. Support was provided by the British Department for International Development (DFID) for this endeavor, which has just been completed. Ipas and Pathfinder/Peru recently conducted a series of rapid assessment visits to four project hospitals to evaluate service quality and prospects for sustainability of improvements (Benson and Huapaya, 2002).

In spite of this progress, several key questions about the future of PAC in Peru remain unanswered. First is the extent to which the changes already implemented in PAC services will be sustained. Second is the lack of availability of PAC services in remote parts of the country, where high rates of maternal mortality persist. Finally, under the current conservative Ministry of Health, negative attitudes and policies toward reproductive health programs in general imply an uncertain direction for postabortion care expansion.

The study described in this report is a follow-up to the original research conducted at Hospital Carrión in 1996-98. The goal of the present study, carried out from 2000-02, was to determine the sustainability of the PAC intervention introduced in the hospital and the extent to which the outcomes of the intervention have continued.

\footnotetext{
${ }^{2}$ Manual vacuum aspiration (MVA) is a safe, effective technique for uterine evacuation of incomplete abortion up to 12 weeks of pregnancy (Greenslade, et al., 1993).
} 


\section{PROBLEM STATEMENT}

\section{Operations Research on Postabortion Care}

A number of studies conducted in Latin America and Africa have assessed the effect of hospital-based PAC interventions on service quality, availability and/or cost. Few projects have included comprehensive PAC interventions, that is, improvements in clinical services, family planning and other reproductive health care. Rather most interventions have focused on a single component of PAC such as changes in clinical practice or linkages to family planning. For example, improvements in clinical care were documented in Egypt, including a switch from SC to MVA, for treatment of incomplete abortion (Huntington, et al., 1995). Still other studies concentrated on the addition of family planning to abortion treatment services, resulting in increased provision of contraceptive information, higher rates of contraceptive method acceptance and/or greater staff satisfaction (Solo et al., 1999; Díaz et al., 1999; Farfán et al., 1997; Távara Orozco and Ramírez Jiménez, 1996). In Zimbabwe, postabortion patients who received family planning counseling and services in the hospital had fewer unplanned pregnancies and repeat abortions twelve months later than those patients who did not receive family planning (Johnson et al., 2002).

Apart from the original study at Hospital Carrión in Peru, two projects have examined a range of outcomes related to comprehensive, hospital-based PAC services. Studies in Bolivia and Mexico reported increased use of MVA and family planning acceptance, along with improvements in medical information provided to patients (Billings et al., 2001; Langer et al., 1999).

\section{Sustainability of PAC Interventions}

In spite of expressed concerns from international officials and leaders of developing countries about the long-term sustainability of health interventions, a number of unanswered questions remain about the issue. Few projects are systematically evaluated after outside assistance has terminated.

Furthermore, definitions of sustainability vary. For example, family planning programs in Latin American NGOs have received support from USAID for several decades, but are currently faced with large decreases in assistance. These organizations have focused their efforts on financial sustainability through cost recovery and income generation (Bratt et al, 1998). Other development experts have emphasized the strategic capacity of organizations to sustain programs, such as policy development, planning, resource generation and monitoring (Shepperd, 1991).

Global assistance for postabortion care activities from USAID and other bilateral and multilateral organizations increased during the 1990s. Now, there is growing recognition that sustainability is a priority, even at this early stage, particularly as PAC interventions are expanded from demonstration projects to national, "scaled-up" programs (Engender Health and Ipas, 2001; Benson, 1998). There is also a need for descriptions of the 
institutional and environmental characteristics that influence the sustainability or “institutionalization” of health interventions (Bossert, 1990; Shepperd, 1991).

For purposes of the present study, sustainable services are those which have been institutionalized or incorporated into routine hospital practices and whose outcomes have continued after external support has ended. Hospital Carrión has received no outside technical or financial assistance for postabortion care since the original study concluded in early 1998. PAC services have remained under the full responsibility of the Department of Obstetrics-Gynecology and its emergency room services, and the hospital itself. The present study is the first known research to examine how well a PAC intervention and resulting improvements have been maintained over the long term. 


\section{STUDY METHODOLOGY}

\section{Objectives and Definitions of Sustainable Outcomes}

Specific objectives of the study were to:

1. Assess changes over time in the following outcomes:

1a. Use of MVA for treatment of incomplete abortion. In the 1996-98 research, MVA use for clinically-appropriate patients increased from $0 \%$ in the pre-intervention stage to $89 \%$ in the final month of the post-intervention stage. Three months after the conclusion of the original study, in May 1998, MVA use was virtually universal, used for $95 \%$ of patients. In planning for the present study, we anticipated some drop-off since that time. There are no guidelines for an "acceptable" percentage of patients treated with MVA as an indicator of PAC program sustainability, although a 50\% figure and above is considered adequate coverage based on Ipas's global experience. For this study, we defined average monthly MVA use of $70 \%$ and up as evidence that the technique had been institutionalized into hospital practice.

1b. Provision of family planning information to postabortion patients. In the original study, $18 \%$ of patients in the pre-intervention stage reported being informed about family planning during their stay, while $78 \%$ of post-intervention women did so. Drops in these high percentages were likely to have occurred since then. There is no universal indicator of the sustainability of postabortion family planning as measured by a minimum percentage of patients who are given information and methods. Ideally, all postabortion patients should be given information prior to leaving the health facility, although the delivery of contraceptive methods will vary by site and patient population. With successful institutionalization of family planning counseling into overall PAC services at Hospital Carrión, we anticipated that no more than a 20-percentage point drop would have occurred for the present study. This expected decrease was based on the sample size needed to detect statistical significance as well as the estimated percentage change that could be considered a reasonable measure of the extent to which postabortion family planning had been programmatically institutionalized.

1c. Acceptance of contraception by postabortion patients prior to discharge. In the original research, just $2 \%$ of patients in the pre-intervention stage left the hospital with a contraceptive method, increasing to $59 \%$ of women in the post-intervention. Similar to the family planning information outcome, we expected a decrease in the percentage of PAC patients receiving a method during the current study. Therefore, our definition of a sustainable outcome was a no-greater-than 20-percentage point drop from the post-intervention stage to the current study.

1d. Provision of medical care information to patients. Improvements in the delivery of medical information were one of the more challenging aspects of the PAC intervention. Pre- and post-intervention increases for some variables were statistically significant, but in absolute terms, the low percentages indicated that most postintervention patients were not given comprehensive information about warning signs or 
follow-up clinical care. For other medical care variables, percentages of affirmative responses actually declined between the pre- and post-intervention stages.

We believed it unlikely that the delivery of medical care information would improve from the post-intervention stage to the time of the present study. It was reasonable to expect that the provision of medical care information would remain weak and unlikely to be considered well-institutionalized. However, we anticipated that the medical care information percentages would at least remain the same.

1e. Length of hospital stay by postabortion patients. During the original study, with a switch from inpatient to outpatient PAC services, average total length of stay (ALOS) dropped from 33.3 to 6.4 hours. As with previous outcomes, there is no generally accepted, ideal ALOS. Some increase may have occurred since the conclusion of the original study due to changes in administrative procedures or increases in the overall ob-gyn caseload. We therefore defined successful institutionalization of outpatient PAC as a 10-hour-or-less ALOS.

1f. Resources used by the hospital and patients for PAC services. The estimated average cost per patient for PAC decreased from US \$118.73 in the pre-intervention stage to US $\$ 45.13$ in the post-intervention. This drop in costs was largely attributable to the

marked decline in patient stay as outpatient services became the norm. Costs of care vary dramatically across countries. Within the same hospital, and with minimal change in the ALOS, however, we did not anticipate a large change in the estimated cost of PAC.

2. Describe the organizational and environmental contexts that have influenced changes in the PAC outcomes.

\section{Study Design}

A diagram of the original and present studies is provided in Annex 1. The original study utilized a pre-post intervention design with no control group. Pre-intervention data (stage 1) were collected in 1996 for clinical care, postabortion family planning, medical care information, length of stay and cost outcomes. Following implementation of the PAC intervention previously described, post-intervention data were obtained in 1997 to measure changes in these outcomes (stage 2). The present study, conducted in 2000-02, consists of a third, follow-up stage of data collection to document the long-term continuation of outcomes (stage 3 ).

A control hospital was not included in the original project's design due to resource constraints and ethical concerns about offering a safer clinical technique (MVA) only to patients at the study hospital. The long-time unchanged nature of the hospital's traditional postabortion treatment, the extensiveness of the intervention and the timeliness of the stage 2 data collection make it unlikely that the changes seen in stage 2 would have been due to factors other than the intervention itself. 


\section{Data Collection}

The hospital-based data collection was conducted by seven obstetrices, under the supervision of a field supervisor. Obstetrices are professional, university-trained midwives who provide most of the reproductive health care offered in Peru, and who are knowledgeable of clinical procedures and the organization of emergency ob-gyn services. Prior to the initiation of data collection, the obstetrices and field supervisor participated in training to familiarize the team with the study instruments, review informed consent documents and procedures to protect confidentiality, practice administration of patient interviews and conduct an actual interview, under supervision, with a family planning client.

The following describes the data collection activities of the present study:

Surgical Logbook Review (objective la)

Following each evacuation procedure, the resident physician or emergency room obstetriz notes information on the patient, including the diagnosis, uterine size and evacuation technique, in a logbook kept in the emergency room. Using a form similar to one developed for the original study, a project data collector recorded information from the logbook for each month from June 1998 through December 2000.

Patient Exit Interviews (objectives 1b, 1c, 1d)

The project investigator developed a patient interview questionnaire, selecting closeended questions from the instrument administered in the original study. Topics covered included patient sociodemographic and reproductive health characteristics, family planning and medical care information provided during the hospital stay, and contraceptive method provided before discharge. Interviewers were stationed in the obgyn emergency room on a 24-hour-a-day basis from late October, 2000 to January 20, 2001, except for four days during the Christmas and New Years holidays. Emergency room staff were instructed to ask PAC patients if they would be willing to discuss possible participation in an interview about the services they had received. In the case of minor patients (under 18 years of age and not married or in a consensual union), a parent or adult accompanying the patient was first contacted.

With a positive response, an interviewer then asked the patient for permission to conduct the interview. For minor adolescents, consent was first obtained from a relative and then from the woman herself. The interviewer thoroughly reviewed the printed consent form with the patient. Patients could provide written or verbal permission and were given the option of receiving a copy of the permission form if they wished.

Interviews were conducted in the emergency room in a small room with a door, prior to the patient's departure from the hospital. Each interview lasted between 20 and 30 minutes. Patients were given family planning and medical follow-up care brochures at the conclusion of the interview if they had not previously received this information from the hospital staff. 


\section{Clinical History Form (objective 1d)}

A clinical history form, also used during the original study, included information on the woman's clinical condition, type of treatment received (including pain medications), treatment-related complications and other information. Following the patient interview, the data collector completed the clinical history form, extracting information from the patient's medical chart. The provider for that patient was contacted for any incomplete information on the chart.

\section{Length of Stay and Resource Data Collection (objectives le and 1f)}

Data collectors conducted a rapid assessment, time-motion study, observing a small sample of PAC patients from arrival at the emergency room until departure. Data collection forms were similar to those used in the original study. The data collectors reviewed a consent form with all patients and verbal permission was obtained prior to the start of the observation process. Observers recorded the length of time a patient remained at each point in the process of care, the type of provider and amount of time spent attending the patient, and the type and quantity of medications, supplies and equipment utilized.

For cost estimates, the hospital provided information on staff salaries and benefits and pharmacy/central supply items. In the original study, the investigators obtained detailed financial information on the hospital's 1995 operating costs, which were used to calculate overhead cost as a component of total cost of care. This information was available as part of a World Bank health sector reform project in which the hospital was participating at that time. During data collection for the present study, the hospital experienced massive changes in leadership at all levels, resulting from the new presidential administration that succeeded President Alberto Fujimori following his abrupt departure from Peru in October 2000. As a result, accurate, detailed and current operating cost information was unavailable; the previously-collected overhead data were therefore utilized.

To calculate average out-of-pocket costs paid by patients for their care, women were asked to show their receipts for hospital fees, medications and other items to the data collectors, who recorded this information. Both hospital costs and patient costs are reported in US dollars at the exchange rate at the time of data collection.

\section{Supplies and Equipment Inventory (objective 2)}

A checklist to assess the availability of human and physical infrastructure, medications, supplies and equipment during the entire process of care was developed. Seventeen checklists were administered at randomly-selected times on weekdays, weekends and on different shifts.

\section{Provider and Policymaker Interviews (objective 2)}

Four open-ended question guides were developed for each category of key informant interviewed: providers at Hospital Carrión, administrators/policymakers at Hospital 
Carrión, MINSA officials and representatives of international organizations working on PAC in Peru. While there was some overlap in questions among the guides, providers at the hospital were asked about such areas as training and supervision, availability of supplies and equipment, and clinical and administrative procedures. The guide for hospital policymakers covered topics such as changes resulting from the study, benefits/problems of current services and political support for the services. MINSA officials and those from international agencies responded to questions about the overall sustainability of services at the hospital and the potential for utilizing the lessons learned from Hospital Carrión in other facilities.

Two experienced qualitative researchers conducted the interviews, one completing five interviews and the other, eight. A letter of introduction was first sent to each key informant and the interviewer followed up with a phone call to set up an appointment. Interviews were conducted in a location of the respondent's choosing, ranging from the hospital itself to a private medical clinic to a café. Each respondent read a consent form and gave verbal permission for the interview. All interviews were taped with the permission of the interviewee and later transcribed for data analysis.

\section{Sampling}

\section{Patient Exit Interviews, Clinical History Forms and Resource Component}

For patient interviews, women presenting at the Hospital Carrión ob-gyn emergency room for treatment of incomplete abortion of 12 weeks or less and no additional complications (e.g., septicemica, uterine perforation, etc.), and who gave permission for an interview, were admitted to the study. No patients refused to participate in an interview. These eligibility criteria are comparable to those for the stage 2 (postintervention) stage of the original study. ${ }^{3}$ Because use of MVA in the emergency room had become virtual standard practice for uterine evacuation in both stages 2 and 3, all study patients were treated with MVA.

In each of stages 1 and 2, 102 patients were included in the sample. For the present study, our sample size calculations resulted in a goal of 100 patients. We exceeded the original sample projections and interviewed 125 patients. During data analysis, six patients were excluded, most because they exceeded clinical admission criteria for duration of pregnancy. Therefore, interviews and corresponding clinical history data from 119 patients are included in this report.

For the length of stay and resource component of the study, an additional purposive sample of 18 PAC patients was selected and asked to participate in the study. These patients met the same eligibility criteria as those participating in the exit interviews.

\footnotetext{
${ }^{3}$ In stage 1 (pre-intervention) of the original study, patients up to 16 weeks of pregnancy were admitted. During that time period, the hospital protocol was to hospitalize postabortion patients at all gestations of pregnancy, with uterine evacuation performed with SC in an operating theatre.
} 


\section{Key Informant Interviews}

A total of 13 qualitative, key informant interviews were conducted. The investigator and study team compiled a list of potential respondents who were sufficiently knowledgeable about the PAC services at the hospital and in Peru as a whole, and the resulting number of key informants was lower than originally anticipated. Frequent turnover of leadership at the hospital and at the Ministry of Health during the time of the study led to the exclusion of some new officials who were unfamiliar with postabortion care in Peru. We did, however, interview both current and previous providers and policymakers who are or were involved in PAC in Hospital Carrión or elsewhere.

\section{Data Analysis}

All patient interview and clinical history data were entered in Stata 7.0 for Windows (StataCorp, College Station, Texas, 2001). Data from stage 1 and stage 2 were converted into Stata and merged into the stage 3 data file, so that data from all three stages were available in one file for easier comparisons. Logbook data, patient observation and other cost data from the resource component and the supplies and equipment inventory data were entered and analyzed in Microsoft Excel. Transcriptions from the key informant interviews were entered and analyzed in CDC E-Z Text 3.06 (Conwal Incorporated, Atlanta, Georgia, 1998).

Percentages and means were calculated for each stage for key variables from the patient interviews and clinical histories. Pearson's Chi-square was used to assess statistically significant differences (at a 95\% significance level, 2-tailed test) for categorical variables. Student's t-test was used for significance testing of continuous variables. While percentages and means are provided for all 3 stages, significance testing is reported only for comparisons between stages 2 and 3 to focus on the sustainability of the outcomes from the post-intervention period to the present study.

Monthly percentages of appropriate patients treated with MVA over time are reported. Total average length of stay for each of the three stages is provided, along with the average amount of time spent in the pre-procedure, procedure and post-procedure periods.

Three cost components were calculated to estimate the total average cost per PAC patient: salaries, medications/supplies/equipment and overhead. Average salaries and benefits were calculated, based on the type of provider and amount of time spent with the patient. Unit costs of medications and supplies were obtained and then pro-rated to reflect actual, average quantities used for patients. Due to the longevity of medical equipment used, these costs were valued at almost zero (e.g., speculum, forceps, etc.). While MVA instruments were donated during the original study, purchase of these instruments was included in the calculations to present a more realistic estimation of postabortion care costs. Costs of MVA syringes and cannulae were based on individualpurchase prices of Ipas-produced instruments from a Peruvian distributor at the time of the study, and included national taxes and customs charges. With proper infection prevention practices, MVA syringes and cannulae can be safely re-used. Per-patient 
MVA costs were based on an estimated 50 uses per syringe and 20 uses per cannula, although providers around the world historically report a much higher number of uses per instrument. Contraceptive commodities costs were based on purchase prices to the national family planning program of the Ministry of Health but did not include taxes, customs fees or distribution costs.

Hospital operating expenditures for 1995 were used to calculate overhead costs for all three stages. A cost-per-bed minute was calculated, based on the percentage of overall hospital expenses utilized for hospitalization (inpatient care) and the annual bed occupancy rate. The average length of stay in minutes (based on patient observation) was then multiplied by the cost-per-bed minute to determine the average overhead cost per patient.

Data from the key informant interviews were analyzed by questions asked of respondents and by topical codes, such as training by provider category, strengths and weaknesses of current services and level of support from hospital staff and officials. Consistencies and disagreements across questions and by theme were identified. To help explain the sustainability of PAC services, key factors that facilitated or hindered sustainability were identified. 


\section{MAJOR FINDINGS}

Findings corresponding to each of the specific study objectives, 1a through 1f, are presented below.

\section{Use of MVA (Objective 1a)}

Our logbook review indicated that in the year 2000, a total of 455 women at 12 weeks or fewer of pregnancy received treatment for incomplete abortion at Hospital Carrión, an average of 37.9 patients monthly. These figures have not varied markedly in the last several years, with 455 patients treated in $1998^{4}$ and 437 in 1999 . In $1999,72 \%$, and in $2000,75 \%$ of all incomplete abortion patients treated at the hospital presented at 12 weeks or fewer of pregnancy.

Figure 1 portrays the percentage of clinically-appropriate patients treated with MVA from September 1996, the month prior to initiation of the stage 1 data collection, through December 2000. Key events related to PAC services are noted. The initial provider training courses were conducted in early 1997 and the new ob-gyn emergency room opened in July $1997 .^{5}$ Since then there has been a steady increase in the use of MVA. Since late 1997, MVA has been used for almost all patients, with a few scattered exceptions (in September 1998, the technique for uterine evacuation was not recorded for 6 of 42 patients). In the year 2000, 99\% of PAC patients were treated with MVA.

\footnotetext{
${ }^{4}$ Logbook data for the month of April 1998 were not available.

${ }^{5}$ During our first visit to the hospital in mid-1995, officials there informed us of their plans to build an obgyn emergency room. Funds for construction of the new unit were provided by MINSA. PAC is just one of a number of ob-gyn services offered in the emergency room.
} 
Figure 1. Monthly percentage of clinically-appropriate postabortion patients treated with MVA (September 1996-December 2000)

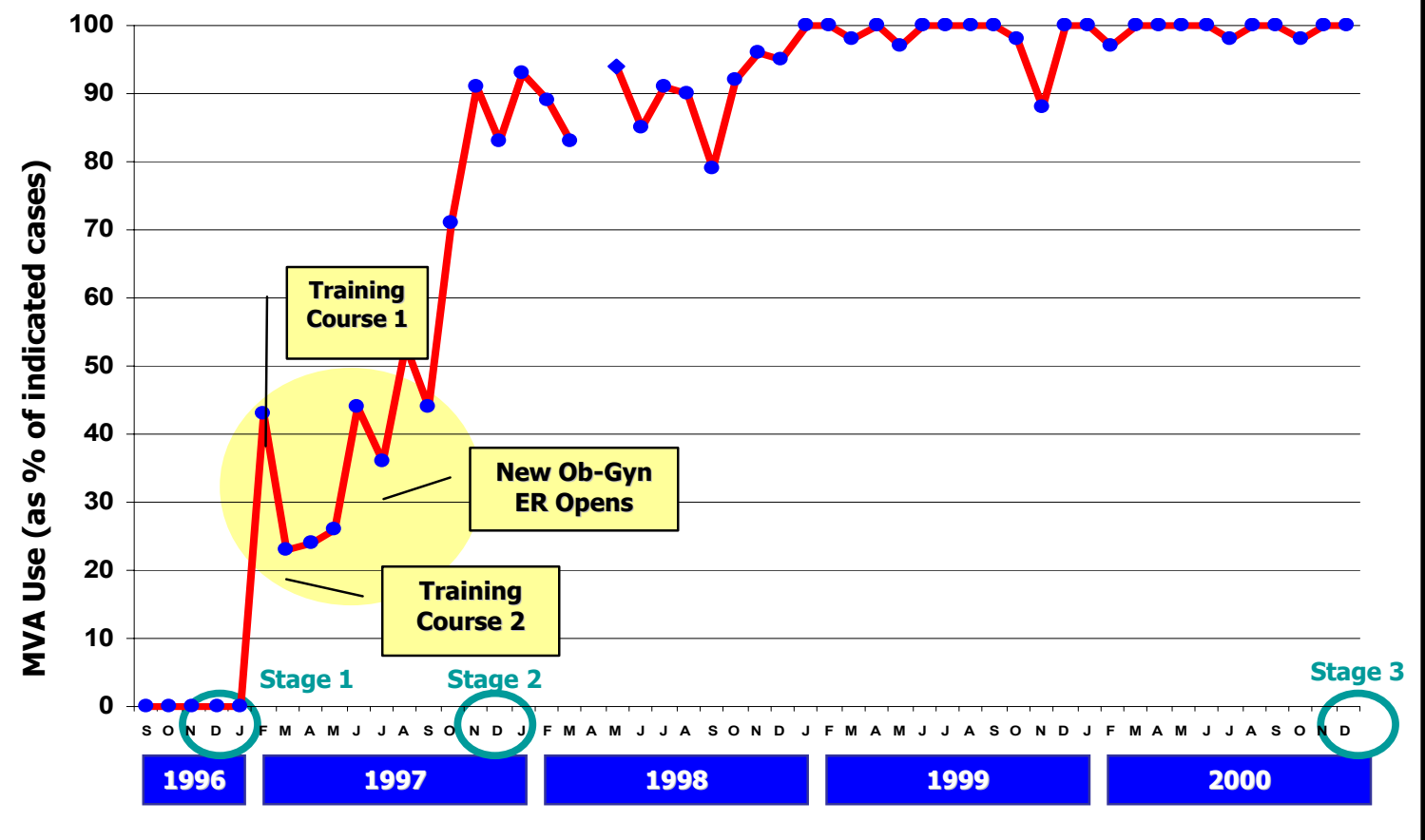

With maintenance of MVA use at an average of $98 \%$ of patients or greater for two straight years (1999 and 2000), there is strong evidence that the clinical technique has been well-incorporated into routine hospital practice. Our projected indicator of sustainability of MVA use, defined as $70 \%$ or more of cases, was surpassed.

\section{Characteristics of Patients}

This section describes the sociodemographic and reproductive health characteristics of the patients interviewed in stages 1,2 and 3 .

Table 1 provides information about the age, educational level and employment of PAC patients by stage. There were slightly more adolescents in stage 3 and a drop in the percentage of women 20-24 years of age from stage 1 to stage 3 . The level of education among the groups was also similar, increasing from stage 1 to stage 2, and remaining comparable in stage 3. For stages 2 and 3, about one-quarter of patients had more than 12 years of education. The majority of patients were housewives. Other employment responses are classified by requirements of Peruvian law for medical and social security benefits, for example, certain types of workers such as employees of companies and domestic workers receive benefits, while mobile vendors and operators of small shops are not covered. There were no statistically significant differences between women in stages 2 and 3 for the age, education or employment variables. 
Marital status was obtained from patients' medical charts in stages 1 and 2, with the majority ( $84.4 \%$ and $73.7 \%$, respectively) of women either married or in a consensual union. However, in stage 3, emergency room staff did not record marital status on the charts. This gap could have been due to the possibility that in emergency situations, with short lengths of stay, only the most essential and minimal information is collected by staff. During stage 2 data collection, the emergency room had just opened, and staff were accustomed to long patient stays and more opportunities for taking patient histories.

Table 1. Sociodemographic characteristics of postabortion patients by stage, $\%$ of respondents

\begin{tabular}{|l|c|c|c|}
\hline \multicolumn{1}{|c|}{ Variable } & Stage 1 & Stage 2 & Stage 3 \\
\hline Age & $\mathbf{n = 1 0 2}$ & $\mathbf{n = 1 0 2}$ & $\mathbf{n = 1 1 9}$ \\
\hline $15-19$ & 12.8 & 12.8 & 17.7 \\
\hline $20-24$ & 30.4 & 23.5 & 19.3 \\
\hline $25-29$ & 24.5 & 24.5 & 26.1 \\
\hline $30-34$ & 16.7 & 16.7 & 16.8 \\
\hline $35-39$ & 9.8 & 17.7 & 11.8 \\
\hline $40-44$ & 5.9 & 4.9 & 6.7 \\
\hline $45-49$ & 0.0 & 0.0 & 1.7 \\
\hline & mean: 27.1 & mean: 27.8 & mean: 27.9 \\
\hline Educational Level & & & 10.9 \\
\hline$<7$ years & 23.5 & 12.8 & 63.0 \\
\hline $7-12$ years & 62.8 & 63.7 & 26.1 \\
\hline$>12$ years & 13.7 & 23.5 & 1.7 \\
\hline Employment & & & 57.1 \\
\hline Housewife & 62.8 & 59.8 & 13.3 \\
\hline Employed with benefits & 17.7 & 19.6 & 8.8 \\
\hline Employed without benefits & 10.8 & 2.0 & \\
\hline Other & 8.8 & & \\
\hline None/unknown & 0.0 & & \\
\hline
\end{tabular}

The reproductive history and goals of PAC patients interviewed are presented in Table 2 . The percentage of women for whom this was their first pregnancy was almost identical in stages 1 and 3, with the largest percentage in all stages seen among stage 3 patients who had had 2-3 pregnancies (52.1\%). Women with 4 or more pregnancies dropped gradually from stage 1 to stage 3 . There were no significant differences between stage 2 and stage 3 patients in the mean number of pregnancies or living children.

When asked if their current pregnancy was desired, just over 1/3 of women responded affirmatively in each of the 3 stages. Between $20-30 \%$ of patients indicated that they did 
not wish to have a future pregnancy. For those who wanted a repeat pregnancy, about one-half in stages 1 and $3(50.7 \%$ and $46.7 \%$, respectively) wanted to wait more than 2 years. No significant differences were found between stages 2 and 3 for current and future pregnancy desires.

Table 2. Reproductive history and goals of postabortion patients by stage, $\%$ of respondents

\begin{tabular}{|l|c|c|c|}
\hline \multicolumn{1}{|c|}{ Variable } & Stage 1 & Stage 2 & Stage 3 \\
\hline Number of Pregnancies & $\mathbf{n = 1 0 2}$ & $\mathbf{n = 1 0 2}$ & $\mathbf{n = 1 1 9}$ \\
\hline 1 & 21.8 & 32.4 & 21.9 \\
\hline $2-3$ & 44.6 & 39.2 & 52.1 \\
\hline$\geq 4$ & 33.7 & 28.4 & 26.1 \\
\hline & Mean: 3.0 & Mean: 2.7 & Mean: 2.9 \\
\hline Number of Living Children & & & 31.1 \\
\hline 0 & 26.7 & 36.3 & 58.8 \\
\hline $1-3$ & 61.4 & 54.9 & 10.1 \\
\hline$\geq 4$ & 11.9 & 8.8 & Mean: 1.4 \\
\hline & Mean: 1.6 & Mean: 1.3 & 33.6 \\
\hline Wanted Current Pregnancy & 37.4 & 36.3 & 20.7 \\
\hline Desire No Future Pregnancy & 29.7 & 23.7 & 1.1 \\
\hline Timing of Future Pregnancy & & & 52.2 \\
\hline Within 3 months & 1.5 & 8.6 & 46.7 \\
\hline 4 months-2 years & 47.8 & 48.6 & \\
\hline$>$ 2 years & 50.7 & & \\
\hline
\end{tabular}

Table 3 provides information on the contraceptive history of PAC patients. Significantly more women in stage 3 vs. stage 2 had previously heard of family planning and had ever used a contraceptive method. Over half of women in stage 1 were using a contraceptive method at the time they became pregnant, although $60 \%$ of use was periodic abstinence. Although fewer women in stages 2 and 3 than in stage 1 were using a method when they became pregnant, the largest percentage of use $(65.4 \%$ and $42.4 \%$, respectively) also consisted of rhythm. It is noteworthy that for those patients in stage 3 who were using a method at the time of pregnancy, $21.2 \%$ were using oral contraceptives. 
Table 3. Contraceptive history of postabortion patients by stage, $\%$ of respondents

\begin{tabular}{|l|c|c|c|}
\hline \multicolumn{1}{|c|}{ Variable } & Stage 1 & Stage 2 & Stage 3 \\
\hline Contraceptive knowledge & $\mathbf{n = 1 0 2}$ & $\mathbf{n = 1 0 2}$ & $\mathbf{n = 1 1 9}$ \\
\hline Ever-use of contraceptive method & 98.0 & 92.2 & $99.2^{* *}$ \\
\hline Method use at time of pregnancy & 52.6 & 77.4 & $89.8^{* *}$ \\
\hline
\end{tabular}

${ }^{* *} \mathrm{p}<.05$ for stages 2 and 3

In sum, the sociodemographic and reproductive health characteristics of PAC patients in all 3 stages were quite similar. The only statistically significant differences between women in stage 2 and stage 3 were for contraceptive knowledge and ever-use of contraception. PAC patients participating in the studies were typically housewives in their late 20's, fairly well-educated, with 1 to 3 living children. For most, the current pregnancy was unwanted or unplanned and almost no women wanted an immediate, repeat pregnancy, preferring to delay or stop childbearing altogether. Women participating in the studies had high levels of contraceptive knowledge and use, with a sizeable minority using some type of method when they became pregnant.

\section{Postabortion Family Planning Information and Services (Objectives 1b and 1c)}

A major challenge in the provision of high-quality PAC services is the lack of linkages between emergency treatment services and the provision of contraceptive counseling and methods to patients. Women who seek a clandestine abortion for an unwanted pregnancy and turn to a hospital for treatment of resulting complications often leave the facility without the information and means necessary to prevent a repeat unwanted pregnancy.

As seen in Table 4, the stage 1 data from Hospital Carrión confirmed the situation found in many Latin American hospitals: just over one-third of postabortion patients reported having been told about the risk of an immediate pregnancy, even before the return of menses. Even fewer women were informed about family planning by hospital staff and almost no women actually received a contraceptive method prior to leaving the facility. The stage 2 reports from PAC patients demonstrate the effects of the intervention, in which all three family planning indicators showed major improvements compared to stage 1 , all at significant levels.

As PAC services have become more routine, the upward trend has continued to stage 3 . Almost three-quarters of patients indicated that hospital staff told them about the risk of an immediate pregnancy, almost $90 \%$ reported receiving family planning information and $87 \%$ received a method on site prior to departure from the hospital. 
To assess the effect of potential confounders on the association between receipt of a contraceptive method in the hospital and stages 2 and 3, we tested logistic regression models, controlling for contraceptive knowledge, ever-use of a method and method use at the time of pregnancy. The unadjusted odds ratio (OR) for method acceptance prior to hospital discharge comparing stage 3 to stage 2 was 4.51 ( $95 \%$ confidence intervals [CI], $2.33,8.70, \mathrm{p}<0.00)$. Controlling for ever-use of a method reduced the OR to $4.04(95 \%$ CI, 2.05, 7.96, $\mathrm{p}<0.00)$. Contraceptive knowledge and use of a method at pregnancy were also examined as potential confounders, however neither significantly contributed to the overall model, producing less that a $5.0 \%$ change in the unadjusted OR.

Table 4. Postabortion family planning information and methods provided to patients by stage, $\%$ of respondents

\begin{tabular}{|l|c|c|c|}
\hline \multicolumn{1}{|c|}{ Variable } & Stage 1 & Stage 2 & Stage 3 \\
\hline $\begin{array}{l}\text { Informed about risk of immediate } \\
\text { pregnancy }\end{array}$ & $\mathrm{n=102}$ & $\mathrm{n}=102$ & $\mathrm{n}=119$ \\
\hline $\begin{array}{l}\text { Received family planning } \\
\text { information }\end{array}$ & 38.4 & 64.7 & 72.3 \\
\hline Received contraceptive method & 18.2 & 77.5 & $89.1^{\text {** }}$ \\
\hline
\end{tabular}

${ }^{* *} p<.05$ for stages 2 and 3

In both stages 2 and 3, the top two methods provided to patients were injectables $(55.9 \%$ and $45.6 \%$ of acceptors, respectively) and oral contraceptives (39.0\% and $34.0 \%$, respectively). In stage $3,11.7 \%$ of acceptors chose condoms, compared to no women in stage 2 .

As an indicator of the type of information provided to contraceptive acceptors, the patients who selected a specific method were asked if they had been informed about characteristics of that method. Percentages of women responding affirmatively for injectables and oral contraceptives for stages 2 and 3 are provided in Tables 5 and 6 . Responses for stage 1 are not presented because only 2 of 102 women received a method during that stage.

There was only one significant difference in the types of basic information provided about each method between women in the two stages. Almost all women receiving either method were given fundamental information about that method, for example, a repeat injection is required every three months for injectables, pills should be taken daily, etc. The percentage of women receiving additional, more detailed information was insufficient for several variables, for example, the secondary effects of the methods. Given the national controversies about informed choice for female sterilization in the national family planning program, it is noteworthy that a large majority of patients receiving injectables and oral contraceptives stated they were informed about their free choice of a contraceptive method. 
Table 5. Method-specific information on injectables provided to postabortion patients for stages 2 and 3, \% of respondents

\begin{tabular}{|l|c|c|}
\hline \multicolumn{1}{|c|}{ Variable } & Stage 2 & Stage 3 \\
\hline New injection needed every 3 months & $\mathrm{n}=\mathbf{3 3}$ & $\mathrm{n}=\mathbf{4 7}$ \\
\hline Method can alter menstruation & 96.8 & 97.9 \\
\hline What to do if skip a menstrual period & 37.1 & 83.0 \\
\hline Contraindications to injectable use & 9.7 & 48.9 \\
\hline Secondary effects of method & 45.2 & $5.0^{* *}$ \\
\hline What to do if time for re-application of method & 38.7 & 25.5 \\
\hline Informed that method choice was woman's decision & 71.0 & 83.0 \\
\hline
\end{tabular}

${ }^{* *} p<.05$ for stages 2 and 3

Table 6. Method-specific information on oral contraceptives provided to postabortion patients for stages 2 and 3, \% of respondents

\begin{tabular}{|l|c|c|}
\hline \multicolumn{1}{|c|}{ Variable } & Stage 2 & Stage 3 \\
\hline Need to begin pill use immediately & $\mathbf{n = 2 3}$ & 94.3 \\
\hline Need to take pill daily & 100.0 & 97.1 \\
\hline What to do if forget to take pill & 86.4 & 62.9 \\
\hline Secondary effects of method & 52.2 & 31.4 \\
\hline Skipping a pill can result in vaginal bleeding & 40.9 & $14.3^{* *}$ \\
\hline What to do if skip a menstrual period & 21.7 & 11.4 \\
\hline What to do if run out of pills & 31.8 & 40.0 \\
\hline $\begin{array}{l}\text { Informed that method choice was woman's } \\
\text { decision }\end{array}$ & 73.9 & 71.4 \\
\hline
\end{tabular}

${ }^{* *} p<.05$ for stages 2 and 3 
For women receiving a method prior to hospital discharge, $91.5 \%$ in stage 2 and $86.4 \%$ in stage 3 reported being informed about where to receive contraceptive re-supply (not significant). Almost $48 \%$ of stage 2 patients and $18.8 \%$ of stage 3 patients not receiving a method in the hospital were given a follow-up family planning appointment $(p<.05)$.

The postabortion family planning component of PAC services has now become wellinstitutionalized into routine services. In contrast to our expectation that the three main family planning variables (risk of pregnancy, family planning information offered, method provided, Table 4) would decrease in stage 3, the opposite occurred. All three variables improved, two at a statistically significant level. Even after adjusting for potential confounders, stage 3 patients had a greater than four times odds of receiving a contraceptive method prior to leaving the hospital, compared to stage 2 patients. There is a broad range of methods available to postabortion patients, including injectables, oral contraceptives and condoms. The content of family planning information offered to patients is appropriate for some indicators, although improvements are needed for more detailed guidance.

\section{Medical Care Information (Objective 1d)}

Medical care information given to PAC patients includes information about the patient's diagnosis, treatment needed and results of the procedure. Follow-up care information is also important, so that the patient knows what to anticipate as she returns home to her daily routine. Finally, the patient should be knowledgeable about post-operative warning signs that indicate a need for additional medical treatment. The individual medical care indicators are provided in Tables 7-9.

For treatment information listed in Table 7, the hoped-for maintenance of the previous results in stage 3 was confirmed for two variables and in one instance there was statistically significant improvement. Table 8 also shows statistically significant improvements from stage 2 to stage 3 in several types of follow-up care information given to women. Warning signs information decreased for all variables from stage 1 to stage 2 . For all but one indicator, the percentage of women receiving this information increased significantly from stage 2 to stage 3 (Table 9).

Throughout all 3 stages of the studies, the level of medical care information offered to PAC patients has been low. For stage 3, however, there was recuperation of drops suffered in stage 2. While there is still a marked need for improvements in this area, there appears to be a better focus on information given to patients, as the PAC services have become well established. 
Table 7. Treatment information provided to postabortion patients by stage, $\%$ of respondents

\begin{tabular}{|l|c|c|c|}
\hline \multicolumn{1}{|c|}{ Variable } & Stage 1 & Stage 2 & Stage 3 \\
\hline & $\mathbf{n = 1 0 2}$ & $\mathbf{n = 1 0 2}$ & $\mathbf{n = 1 1 9}$ \\
\hline Medical diagnosis & 10.8 & 30.4 & 35.3 \\
\hline Treatment needed & 9.8 & 47.1 & $62.2^{* *}$ \\
\hline Treatment results & 11.8 & 28.4 & 31.1 \\
\hline
\end{tabular}

${ }^{* *} p<.05$ for stages 2 and 3

Table 8. Follow-up care information provided to postabortion patients by stage, $\%$ of respondents

\begin{tabular}{|l|c|c|c|}
\hline \multicolumn{1}{|c|}{ Variable } & Stage 1 & Stage 2 & Stage 3 \\
\hline & $\mathrm{n}=102$ & $\mathrm{n}=102$ & $\mathrm{n}=119$ \\
\hline Personal hygiene & 54.5 & 36.6 & 26.1 \\
\hline When to return to daily routine & 7.9 & 26.7 & 28.6 \\
\hline When menstruation may return & 9.9 & 25.7 & $58.8^{\star *}$ \\
\hline Need to delay sexual relations & 61.8 & 33.3 & $47.9^{\star *}$ \\
\hline
\end{tabular}

${ }^{* *} p<.05$ for stages 2 and 3

Table 9. Warning signs information provided to postabortion patients by stage, $\%$ of respondents

\begin{tabular}{|l|c|c|c|}
\hline \multicolumn{1}{|c|}{ Variable } & Stage 1 & Stage 2 & Stage 3 \\
\hline & $\mathbf{n = 1 0 2}$ & $\mathbf{n = 1 0 2}$ & $\mathbf{n = 1 1 9}$ \\
\hline Intense pain & 81.8 & 20.8 & $30.3^{* *}$ \\
\hline Heavy bleeding & 51.5 & 18.8 & $24.4^{* *}$ \\
\hline Bleeding >2 weeks & 36.4 & 12.9 & $24.4^{* *}$ \\
\hline Fever & 62.6 & 23.5 & $22.7^{* *}$ \\
\hline
\end{tabular}

${ }^{* *} p<.05$ for stages 2 and 3

\section{Other Clinical Findings}

We also collected information about pain management practices used for PAC, as noted on patient's medical charts. Pain medication was provided to almost no patients during the waiting period prior to the evacuation procedure or during the post-operative recovery. This practice was true in all three stages of the studies. The only exception was found in stage 1 , in which $13.7 \%$ of patients were given pain medication during their recovery period. This figure had dropped to $8.1 \%$ of patients in stage 2 and $1.7 \%$ in stage 3. 
In contrast to pre- and post-procedure pain management practices, medications used during the procedure varied over time (Figure 2). Providers of all SC procedures in stage 1 used a combination of drugs for light sedation. This practice shifted in phase 2 , in which use of light sedation dropped to $66.7 \%$ of MVA procedures, paracervical (PC) block was used for $14.7 \%$ and a combination of the two, for $11.8 \%$. Another change occurred by phase 3, in which use of light sedation remained about the same as in stage 2 (62.2\% of MVA procedures), with a combination of light sedation and PC block accounting for $30.3 \%$ of cases.

Figure 2. Pain medications administered during evacuation procedure

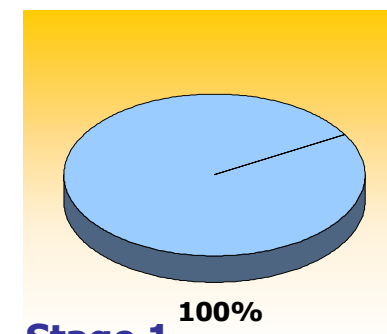

Stage 1

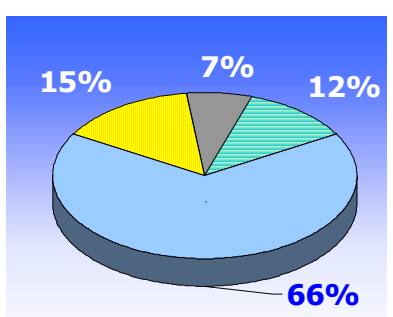

Stage 2

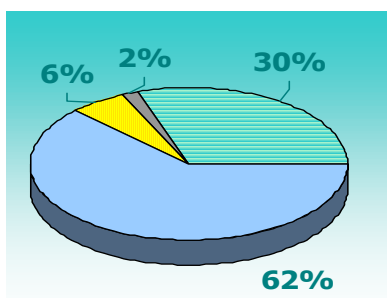

Stage 3

LIGHT SEDATION

PARACERVICAL BLOCK

COMBINATION $\square$ NONE

In order to assess the patient's perspective, our interviewers asked women to rate the level of pain they experienced at different points during their treatment, using a 0 (no pain felt) to 10 (worst pain ever felt) scale. Table 10 provides the mean pain scores by patients interviewed in each of the three stages. Between stages 2 and 3, scores remained about the same during the procedure itself and increased slightly, although significantly, during the post-procedure period. In the pre-procedure period for stage 1, the mean score of almost 6 dropped to just over 4 in stage 2, but increased to almost original levels in stage 3 .

Table 10. Mean pain scores of postabortion patients at different points in the treatment process by stage

\begin{tabular}{|l|c|c|c|}
\hline \multicolumn{1}{|c|}{ Variable } & Stage 1 & Stage 2 & Stage 3 \\
\hline & $\mathrm{n}=102$ & $\mathrm{n}=102$ & $\mathrm{n}=119$ \\
\hline Pre-procedure & 5.8 & 4.1 & $5.7^{* *}$ \\
\hline During procedure & 3.9 & 4.7 & 4.5 \\
\hline Post-procedure & .99 & 1.4 & $1.9^{* *}$ \\
\hline
\end{tabular}

${ }^{* *} p<.05$ for stages 2 and 3

Pain perceptions result from many diverse influences including the physical condition of the patient, her level of fear and anxiety, extent of support from family members, waiting 
time, length of time in contact with staff and verbal and other reassurance provided by hospital personnel. Our study did not attempt to measure the range of complex factors that may affect an individual's perception of pain. However, our time-motion data enabled us to assess the proportion of time spent by hospital staff with patients during each stage of their treatment process.

To better understand possible reasons why the mean pain score in the pre-procedure period increased from stage 2 to stage 3 , reverting to stage 1 levels, we examined the proportion of time patients were in contact with clinical personnel before their procedure. Clinical personnel included attending and resident physicians, medical interns and staff, and student obstetrices. In stage 1, on the average, clinical personnel attended PAC patients just $9 \%$ of their total 5.3 hour pre-procedure wait. For the remainder of the preprocedure period, patients waited without the involvement of clinical staff.

In contrast, in stage 2, the proportion of time patients were attended by staff increased markedly, to $36 \%$ of their pre-procedure wait. This rise resulted from a pre-procedure wait that declined to 2.9 hours, while the absolute amount of staff contact time with patients increased markedly.

During stage 3, staff contact time decreased to $23 \%$ of the overall pre-procedure wait. While the pre-procedure waiting time actually dropped slightly in stage 3 , the absolute amount of time that clinical personnel attended PAC patients declined notably, to slightly more than stage 1 levels.

Almost no patients were given pain medications either before or after their procedure in any of the three stages. The pre-procedure mean pain score dropped in stage 2, when clinical staff spent the largest proportion of time in contact with PAC patients. It is possible that this relatively higher level of staff-patient interaction led to lower perceptions of pain by women as they waited for their procedure. In stage 3 , when staff contact time decreased, pain scores returned to almost those found in stage 1.

\section{Length of Stay and Resources Used for PAC Services (Objectives 1e and 1f)}

Prior to implementation of PAC services (stage 1), postabortion care was categorized as an inpatient service, requiring admission to the hospital and an overnight stay on the obstetrics-gynecology ward. Due to the design of the hospital, postabortion services were dispersed throughout the facility, requiring transport of patients up stairs, on elevators and through a long tunnel to an adjoining building. With the opening of the ob-gyn emergency room, virtually all PAC services are provided in the emergency room (stage 2 ) with the exception of diagnostic procedures such as ultrasound needed for some patients. 
Figure 3. Total average length of patient stay, by stage

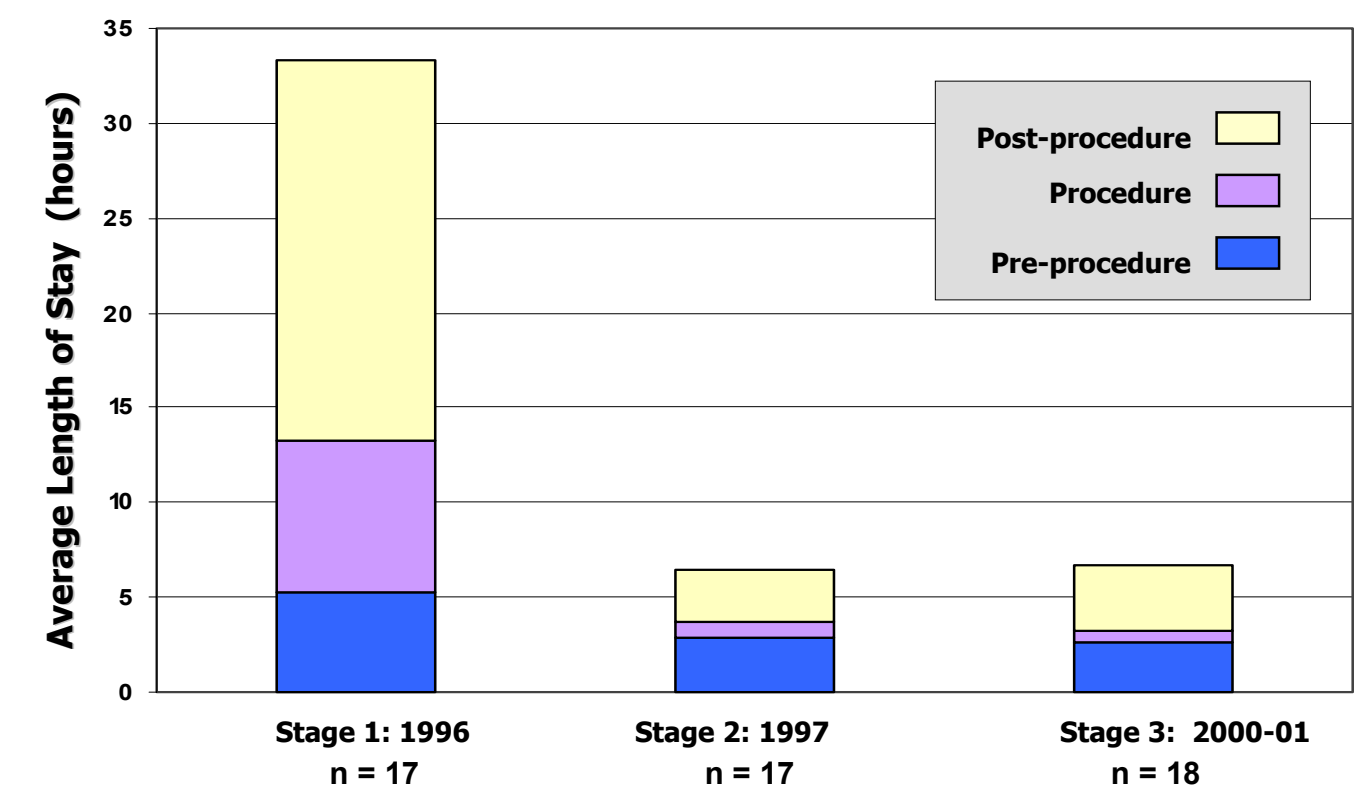

The change from an inpatient to an outpatient service resulted in a large drop in length of patient stay. The average length of stay (ALOS) in stage 1 was 33.3 hours, while in stage 2 , it had declined to 6.4 hours. At the stage 3 data collection point, the ALOS was 6.7 hours, indicating that the outpatient patient stay has been sustained at an almost identical level since 1997 (Figure 3).

One of the indicators of the quality of clinical care is the length of time patients wait from arrival at the health care facility to their evacuation procedure. There is general agreement that delays in treatment should be kept to a minimum due to the emergency nature of postabortion complications, for example, not to exceed two to three hours. In stage 1 , the average pre-procedure wait was 5.3 hours, which decreased to 2.9 hours in stage 2 and dropped slightly in stage 3 to 2.6 hours. In-depth patient interviews conducted during stage 1 identified long waits for care as a major source of patient dissatisfaction.

The excessive length of medically unnecessary post-operative stays on the ob-gyn ward in stage 1 (an average of 20.1 hours, or $60 \%$ of the total stay) led to high costs to the hospital and patients who complained of being abandoned. By stage 2, the post-operative stay had declined to 2.7 hours, and in stage 3 , increased somewhat to 3.5 hours.

Figure 4 provides the estimated average cost of care to the hospital for a PAC patient in US dollars. Salary costs during stage 1 were $\$ 4.93$, costs of medications, supplies and equipment were $\$ 13.82$, and overhead costs were $\$ 99.98$, for a total of $\$ 118.73$. With the shift to outpatient services and related drops in the length of stay in stage 2 , the average 
total cost of care declined markedly to $\$ 45.13$. (The stage 2 salary component was $\$ 5.96$, medications, supplies and equipment were $\$ 19.97$ and overhead costs were $\$ 19.20$ ). It is important to recognize that the savings from stages 1 to 2 do not translate into actual drops in hospital expenditures but rather free up resources to channel into other services offered by the hospital.

Figure 4. Average total cost of postabortion care, by stage

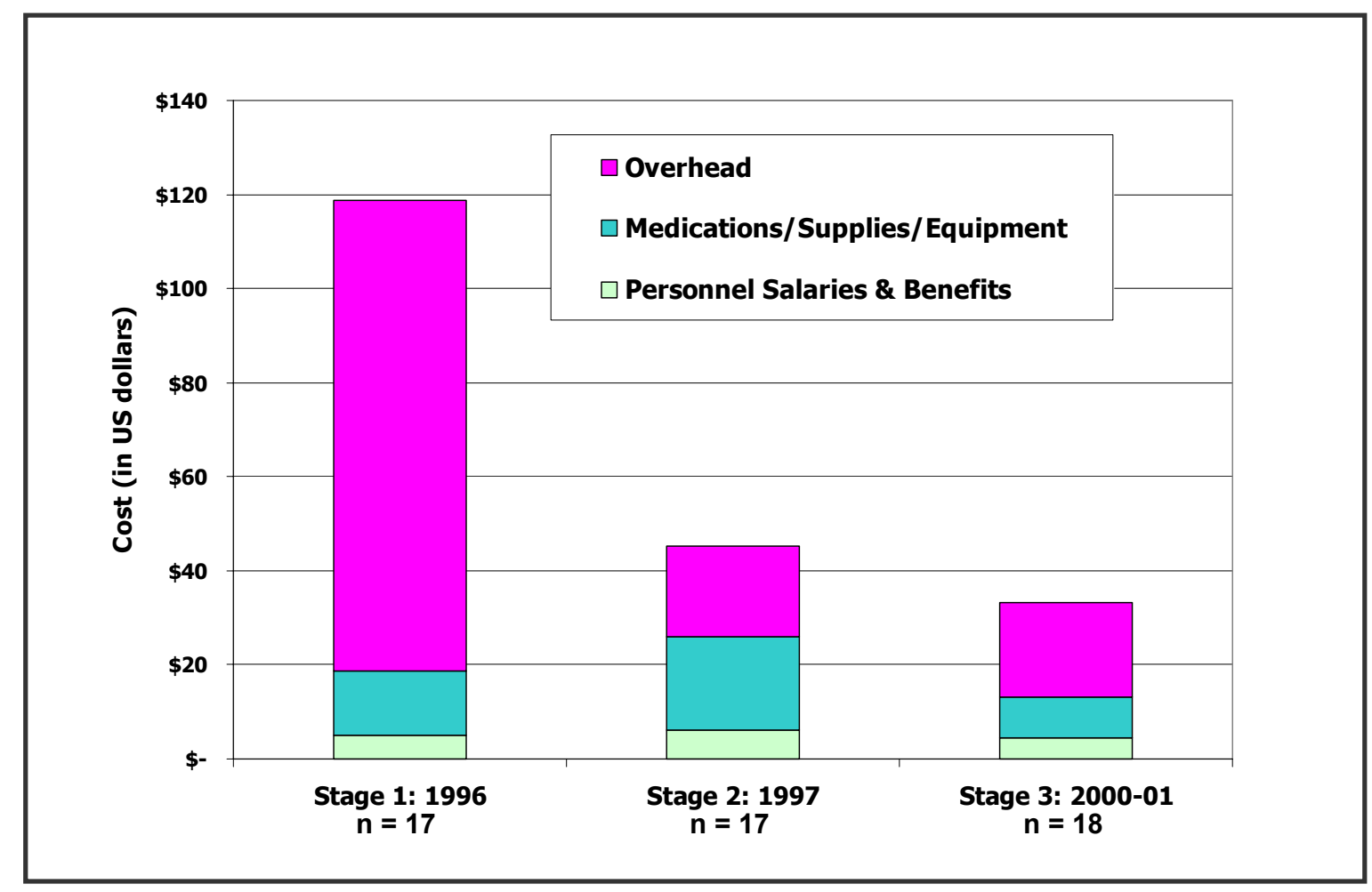

For stage 3, estimated total cost per patient was $\$ 33.45$, comprised of $\$ 4.64$ in salaries, $\$ 8.70$ in medications, supplies and equipment, and $\$ 20.11$ in overhead. The decline in estimated costs from stage 2 to stage 3 could be attributable to stagnant personnel salaries (staff at Hospital Carrión had not received a pay raise in the five years prior to stage 3 data collection), large fluctuations in the costs of medications and supplies in Peru as a whole and the decline in the value of the Peruvian currency, the nuevo sole, vis-à-vis the US dollar between 1997 and 2001.

Out-of-pocket costs for patients include the hospital admission fee, surgical procedure fee, medications and some supplies. Medications and supplies are usually purchased from the hospital pharmacy, although if specific items are unavailable, patients' families make purchases in one of the many private pharmacies surrounding the hospital. In stage 1, out-of-pocket expenses for PAC patients were $\$ 52.98$, while in stage 2, patients paid $\$ 37.40$. The original cost and resource findings---demonstrating the reductions in length of stay and related costs to the hospital with a change to outpatient care---prompted the hospital director to reduce patient fees for patients treated with MVA by one-half, from 
80 soles to 40 soles ( $\$ 32$ to $\$ 16$ ), from stage 1 to stage 2 . By stage 3 , hospital fees had been increased and patients' out-of-pocket expenses averaged $\$ 32.75$.

With a stage 1 cost of $\$ 118.73$, the hospital recovered $\$ 52.98$ from patients, requiring the facility to subsidize an average $\$ 65.75$ per PAC patient. For stage 2 , the average cost was $\$ 45.13$ and average cost recovery from a patient was $\$ 37.40$. Hospital Carrión, therefore, underwrote $\$ 7.73$ per patient. With an estimated cost per patient of $\$ 33.45$ in stage 3 and a payment of $\$ 32.75$, the hospital subsidized $\$ 0.70$. The actual cost recovery to Hospital Carrión is likely to be slightly less because some medications and supplies purchases are made in private pharmacies, rather than from the hospital pharmacy. The hospital and patient cost data suggest, however, that the Hospital Carrión is now recovering almost its full cost of providing PAC services. 


\section{DISSEMINATION OF PROJECT FINDINGS}

The study findings have been well disseminated within Peru, the Latin American region and in the United States. Principal Investigator Janie Benson has made four presentations of the project results in both Spanish and English:

- $129^{\text {th }}$ meeting of the American Public Health Association, Atlanta, Georgia, October 2001;

- Unwanted pregnancy and induced abortion: Public health challenges in Latin America and the Caribbean, regional conference held in Cuernavaca, Mexico, November 2001;

- Meeting of staff of Hospital Carrión, Lima, Peru, November 2001; and

- Making the right to postabortion care a reality, final project dissemination workshop held in Lima, Peru, February 2002.

The dissemination workshop was organized to share the results of three studies conducted by Ipas over the last $1 \frac{1}{2}$ years, all with the goal of facilitating improvements in PAC practices and policies. In addition to the sustainability study, findings of a pilot study to test an improved PAC management information system in a state Ministry of Health system and a national rapid assessment of PAC service availability and quality in Ministry facilities were also presented. This "package" of three studies proved to be an appropriate strategy for exploring PAC at the facility, departmental and national levels.

More than 100 participants attended the February 28, 2002 workshop and leaders from the full spectrum of reproductive health organizations served on panels to introduce and conclude each study presentation (agenda previously sent). These included representatives from the national Ministry of Health, MINSA officials from departments throughout Peru, hospital-based providers and administrators from Lima and other cities, university faculty, representatives of local non-governmental organizations, including women's groups, staff from international reproductive health agencies and representatives from international donor agencies. In addition, two Bolivians were present at the meeting, including the head of reproductive health for the Bolivian Ministry of Health.

The enthusiasm for the topic of PAC in Peru was evident among the participants, both during the question periods and in comments made during the breaks. One guest noted the significance of such a well-attended meeting, convened to discuss an important but still-controversial topic, especially during an era of conservative Ministry of Health leadership. The high maternal mortality ratio in Peru remained of great concern to all attending. Improved PAC quality and accessibility was viewed as an essential and feasible strategy to help address this major problem. Furthermore, there was overall recognition of the need for increased attention to these services at the local and national levels. The tools presented during the meeting, for example, the management information system, were in demand for implementation throughout the country and Ipas 
has subsequently provided the software and accompanying manual to the departmental Ministries of Health requesting this information.

The day following the workshop, March 1, Ipas organized visits for about 30 non-Lima participants to two hospitals with high quality, ambulatory PAC services, Hospital Maria Auxiliadora and the study hospital, Hospital Carrión. In addition to observing the physical organization of services, the participants had the opportunity to talk with physicians and obstetrices involved in service delivery at each site.

Ipas has provided the Spanish set of Power Point slides presented at the workshop to Hospital Carrión for their future use. Further dissemination activities planned include the addition of a summary of the study to the Ipas web site, in both Spanish and English, and preparation of a peer-reviewed journal article. 


\section{DISCUSSION}

The results indicate that the PAC services and related outcomes have been well sustained over the three-year period since the conclusion of the original study. All of the sustainability indicators were met and, in most instances, surpassed. Specifically, the use of MVA for treatment of incomplete abortion, provision of contraceptive information and methods, and delivery of short-stay, outpatient postabortion care at a reasonable cost to the facility are well institutionalized into the complement of services offered in the obgyn emergency room. Several areas of PAC services merit additional attention for desired improvements, including the provision of more comprehensive medical care information, changes in pain management practices, especially prior to and after the evacuation procedure, and increased personnel time spent in direct contact with PAC patients.

The key informant interviews and supplies inventory provide insight into the reasons why the PAC intervention has become institutionalized into routine emergency services. The following section describes the major reasons for PAC sustainability at Hospital Carrión.

\section{Political Leadership and Support for Change}

PAC services at Hospital Carrión have benefited from the commitment of strong leadership from the outset of the original study. The initial request for support came from the then-Director of the National Family Planning Program (now deceased), who was based at the hospital prior to entering the Ministry of Health. Among other motivations, he saw postabortion care as an approach to improve contraceptive services for women who had not been well served by the national family planning program and to help address the high rates of maternal mortality in Peru.

Study staff identified and were in constant communication with key leaders throughout the course of the original study, including those from the ob-gyn department, family planning clinic and the hospital administration, along with officials from the departmental (state) health ministry with responsibility for the hospital. This core group of leaders remained fairly stable until the end of the Fujimori government. For example, the hospital director, identified by one key informant as "very identified" with the PAC program, held her post from 1995-2001. The initial and continuing enthusiasm of these leaders contributed to the implementation of the intervention and its long-term maintenance. One respondent, in fact, termed the hospital group "pioneers" in the promotion of better PAC services.

Different members of the leadership group and, eventually, other staff, responded to different findings to foster their initial and ongoing support of the services. The safety, effectiveness, ease and convenience of the MVA technique were compelling to some. The postabortion family planning component was viewed as essential by many. However, the reduced length of patient stay and related costs to the hospital were critical motivations for change, mentioned repeatedly by many respondents interviewed. The baseline (stage 1) resource findings, demonstrating the long duration of patient stay and the high costs of care to the hospital, were particularly convincing to the hospital director. 
As in many countries in Latin America, Peru's Ministry of Health at that time was focused on increased decision-making authority and resource generation by individual hospitals, so the cost data were especially timely. Although there was initial opposition to changes in how PAC services were offered by several attending physicians, these staff were ultimately convinced by the demonstrated benefits.

These leaders took advantage of what a key informant called the "happy coincidence" of the hospital's previous decision to construct an ob-gyn emergency room. The new unit could now incorporate improved PAC services, not as a vertical, separate service, but as part of the overall package of ob-gyn care offered in that location. Once implemented, the dramatic changes in the quality of postabortion care and length of patient stay were evident to all staff. As one key informant commented, "It was a marker of how difficult and disorganized (PAC services were) beforehand that you could improve quality (and at the same time), reduce costs."

The leadership became quite active in making changes in administrative and clinical procedures. The director worked with various department heads to modify the process for collection of patient fees, so that PAC patients could be attended immediately upon arrival at the hospital, rather than having to wait for care until they and their families gathered the necessary funds. Fees were also reduced at the instigation of the director. As support for the changes spread to the rest of the staff, the leadership remained involved. One member of the group, for example, continues to train and supervise residents in the use of MVA, as well as performing MVA procedures himself so that emergency room personnel can observe clinical technique. While he is still closely linked to the PAC program, the responsibility for resupply of instruments has shifted from him as an individual to becoming a routine process for staff in the emergency room.

Once the services became established, both the hospital leadership and staff were externally recognized for their participation, further reinforcing the improvements. Physicians and Ministry of Health officials from Bolivia and Haiti toured the emergency room in 1999, with the Bolivian group committed to replicating the services in their hospitals. One of the original hospital leaders has conducted PAC training and technical assistance in other Latin American countries during the last several years, under the sponsorship of an international reproductive health NGO. In addition, during the original study, another leader represented the hospital at a regional meeting in Mexico to discuss cost-benefit issues in reproductive health facilities. There appears to be pride in what the hospital has accomplished. As a key informant commented, "The strengths of (our program are) that all the administration is committed and that all the institution has taken part, that we are a model of prestige, that we are well viewed at the national level, including internationally; everyone asks for the "Carrión model."

The services have survived changes in the original leadership that occurred in late 2000 and early 2001, during stage 3 data collection, indicating that PAC has moved from being identified with a single individual or group, to widespread acceptance as a routine service. 


\section{Staff Roles, Training and Supervision}

The primary personnel involved in the delivery of PAC at Hospital Carrión are resident physicians and obstetrices. Obstetrices register patients, administer medications, including those for pain control, assist in the evacuation procedure, provide contraceptive counseling and application of methods, and are responsible for management of stocks of supplies, instruments and contraceptive commodities. Most of these responsibilities are performed by staff obstetrices but since Hospital Carrión is a teaching institution, student obstetrices perform some tasks under supervision, such as postabortion family planning counseling. There are 32 staff obstetrices who rotate at two-month intervals through the various ob-gyn services such as the emergency room, labor and delivery, and the family planning clinic.

Obstetrics-gynecology resident physicians examine and diagnose patients, order medications and laboratory tests, and perform most uterine evacuations. Residents are not permitted to do evacuations until they have completed six months of residency training. An ob-gyn residency lasts three years, with six new residents admitted annually. Other personnel include attending physicians on duty for consultation and supervision and medical interns who perform some limited tasks such as monitoring patients during the recovery period.

The original training in 1997 was conducted in two segments, one focused on the MVA procedure, infection prevention, pain management and provider-patient interaction, and the other covering postabortion family planning counseling and methods. Participants in the courses included three to four attending ob-gyn physicians, five residents covering all three years of residency and four obstetrices. A separate orientation to sensitize other personnel about the needs of PAC patients was also conducted for staff psychologists, social workers, cashiers and dietary staff.

The composition of the original participant group was designed to train those who were the main service providers at that time, second- and third-year residents and staff obstetrices, as well as those who would be future trainers and service providers such as first-year residents. The strategy proved to be advantageous because residents readily adopted the new procedure. According to one respondent, "Perhaps, we had a lot of help from the residents who made the decision to adapt themselves easily to the new method," in contrast to some attending physicians who remained "indifferent" to the new clinical technique. Furthermore, one of the attending physician trainees has gone on to become chief of the ob-gyn department, lending stability to the PAC services even after changes in the original supportive leadership.

Attending physicians subsequently conducted three-day PAC courses for residents approaching the end of their first year, although the training has not occurred recently due to the political upheavals in the hospital. Most training of residents occurs through observing procedures and then performing them under the supervision of a more experienced resident or attending physician. Several respondents indicated that there was a need for periodic refresher training that included both theoretical and practical components. 
The obstetriz is also key to the ongoing success of the PAC services. In contrast to the constant rotation of residents, staff obstetrics are often stable personnel: all of the four originally trained obstetrices still work at the hospital. The wide range of the obstetrices' experience and skill has also benefited the PAC services. Hospital Carrión has an active family planning clinic staffed by obstetrices. These personnel then apply their knowledge to postabortion contraceptive counseling and method provision when they rotate through the ob-gyn emergency room.

Similar to the residents, more experienced obstetrices train others in the various aspects of PAC. One deficit identified by respondents was the lack of sufficient follow-up training of other obstetrices after the original 1997 courses. In addition, while an attending physician subsequently conducted refresher training for some obstetrices, this had not occurred in the $1 \frac{1}{2}$ years prior to the interview. This gap is particularly problematic because of the presence of contract obstetrices, as opposed to permanent staff, who have less background and experience in the hospital's model of PAC service delivery. Furthermore, the ob-gyn emergency service experienced severe reactions by two PAC patients to Fentanil, an analgesic, with a resulting perceived need for training of staff at all levels in the prevention and management of such emergencies.

The comprehensive selection of original trainees, the rapid uptake of the MVA technique by residents, the wide range of responsibilities and skills of the obstetrics, and the institutionalization of the "each one-teach one" approach to training has contributed to the sustainability of the PAC services.

\section{Administrative and Clinical Protocols}

Administrative procedures for patient payments were generally perceived by our respondents as an obstacle to efficient postabortion care. Patient fees represent an important source of income for hospitals in Peru and facility administrators have the authority to establish and modify fees for clinical care, admission tickets and other services. As previously noted, fees for an MVA procedure were increased from 40 to 85 soles about two years ago. The country's deteriorating economic situation since the mid1990's has limited patients' ability to pay for medical care and, in the case of PAC services, payment policies have resulted in longer-than-necessary hospital stays and frustration for emergency room personnel, patients and their families.

PAC patients are required to pay for their MVA procedure upon arrival in the emergency room and hospital social workers are notified if the patient does not have sufficient resources available. Upon review of the situation, the social workers can fully exempt or reduce the amount of the fees owed by the patient. Exemptions are rarely approved for PAC patients. In the words of one interviewee, “...there is a great deal of resistance to exoneration of payments for abortion." In some instances, emergency room physicians or obstetrices intervene on behalf of patients in particularly dire circumstances. Social workers have consequently been nicknamed "the eternal no's" by other hospital personnel. Denial of exemptions for PAC patients, however, is carried out by the social workers as a mandate from the hospital's administration. 
Our respondents emphasized that patients are not denied needed clinical care, even if they do not have funds for payment of fees. When a woman is in a serious or life-threatening condition, emergency room staff attend her immediately. However, as described by one key informant, "The hospital is very drastic in this (economic) sense; here you don't leave if you don't pay." For patients with limited financial means, various approaches have been developed to deal with this policy. Following their uterine evacuation with MVA in the emergency room, these patients may be sent to the ob-gyn floor and hospitalized until their family members can generate the required payments or, in some cases, the patient simply leaves the hospital without informing any hospital staff.

A variation of this practice is making use of the differentiated fee structure for MVA vs. sharp curettage procedures. Patients receiving an MVA procedure are supposed to pay in advance of their care. Providers can then proceed with treatment because they do not have to depend on an evacuation instrument sterilized by the hospital's central supply unit. In contrast, patients arriving for a sharp curettage procedure can delay payment but their invoice triggers a request to central supply for a sterile curettage set. Following the sharp curettage procedure in the operating room, patients are then hospitalized on the obgyn floor. To address payment problems, some patients with few resources may actually receive an MVA, but the official paperwork indicates that they received a sharp curettage. This enables the patient to delay payment, while she recuperates on the ob-gyn floor. Not unexpectedly, the key informants commented on the counterproductive nature of hospitalizing patients who are unable to pay.

It is important to note that PAC patients are not the only patients affected by the country's dire economic straits or the hospital's payment policies. These circumstances affect all patients seeking hospital care for a range of medical problems. Furthermore, it is difficult to know the number or percentage of all PAC patients who are unnecessarily hospitalized following their uterine evacuation procedure. An informal assessment of our data collectors' notes during the patient interviews in stage 3 indicated that this practice occurred in only a very few instances.

During the stage 1 period, high patient fees prevailed and PAC patients were not permitted to be treated until they had paid the hospital. By stage 2, the hospital administration had changed these policies by reducing fees and mandating immediate care. The current payment policies of the hospital reveal a return to the practices seen in stage 1 . In addition, the inefficiencies generated by these policies can lower the quality of care, diminish patient satisfaction, waste personnel time, exacerbate the pressures on staff in the work environment and ultimately cost the hospital more than it might earn in collected patient fees. Furthermore, our cost data indicate that the hospital is now essentially "breaking even" on postabortion care, by collecting via patient fees and purchase of medications virtually the amount required to provide the service. This information should enable the hospital to exempt those patients in desperate economic circumstances, so that the current financial barriers do not negatively impact those women in greatest need.

With respect to clinical protocols, our respondents reported that there are no written, well-disseminated procedures for PAC. Unwritten protocols for various aspects of 
clinical services such as clinical technique, pain management and infection prevention are shared through staff training and supervision. Clinical practice is usually consistent from one patient to another, but may vary by a patient's clinical history or, in some cases, by physician preference. Routine clinical practice, now in place for more than three years, appears to be well established.

\section{Physical and Human Infrastructure}

The initiation of the original study coincided with a major hospital renovation. Hospital Carrión was physically connected to another hospital which had long been closed. The two institutions were brought under one umbrella, to relieve overcrowding in Hospital Carrión, by moving the floors for hospitalization to the re-opened facility and locating improved emergency rooms in Carrión itself. As one of the hospital leaders commented, "The hospital had the good fortune in that moment to receive the offer of being able to do a study about a new model of care for uncomplicated incomplete abortion. I saw it as a good alternative, as a good option and as an opportunity that I couldn't avoid taking advantage of, because doing an analysis of what they offered us, I was seeing that the length of hospital stay, the costs of care were going to decrease tremendously. Then, the hospital was going to benefit and, of course, the patients also."

The new emergency unit facilitated the institutionalization of PAC services in several ways. Almost all components of PAC services were concentrated in the same physical space, which fostered linkages between the clinical treatment process and postabortion family planning. PAC is viewed as an integrated package of services, not simply the use of a new clinical technique, MVA. In fact, several key informants commented that outpatient PAC services can be implemented using other alternatives for uterine evacuation, including sharp curettage and electric vacuum aspiration.

The emergency room setting also helped to improve the efficiency of patient management. For example, patients are not transported from one location to another within the hospital, as was done previously. Furthermore, PAC has become a routine service, offered in the same physical location by the same personnel who attend other obgyn emergencies, rather than a separate program requiring special staff or physical set-up. One interviewee summarized the changes that he had observed, "I believe that there were two very important changes...First, the question of the technique for treatment and second, the organizational question...the organizational question...is the most important, everything is ambulatory management, reduction of costs and the other point is the concept of integration...postabortion care is not only doing an MVA...the resolution of the complication is simple, if you have an incomplete abortion...you do it with curettage or with MVA."

A key informant, and other individuals not interviewed but who have spoken with study or hospital personnel in the past, have criticized the practicality and sustainability of the model. Their argument is based on the premise that few public health facilities have the resources available to construct a new emergency room; hence, the PAC services at Hospital Carrión are not replicable. Other respondents in our study commented that while the emergency room created a pleasant environment for service delivery, a new 
unit is not mandatory for outpatient, good-quality care. Hospital María Auxiliadora, also located in Lima, began outpatient PAC services in the late 1980's without spending new funds for construction. Hospitals in other cities in Peru have re-organized their services for ambulatory care, using a variety of low- to no-cost approaches to link clinical treatment with family planning and reduce patient stays (Benson and Huapaya, 2002). With adequate planning, PAC services in low resource settings can be updated to resemble those in Hospital Carrión, with designs tailored to meet local needs.

The supplies and equipment inventory indicated that the physical infrastructure (lighting, bathroom facilities, availability of water and electricity, etc.) of the emergency room is quite good. With the exception of a backup source of electricity in the event of power failure and a lack of auditory privacy in the admission, clinical examination and recovery areas, the infrastructure was adequate during almost all times that the inventory checklist was administered.

Available resources at the hospital have also fostered the institutionalization of PAC services. The respondents reported that MVA syringes and cannulae are routinely available, although occasionally, if a large number of PAC patients arrive simultaneously, there are delays while the instruments are re-sterilized. The results from the inventory checklist indicated that a complete MVA set(s) is not always present. A double-valve syringe was available during $82 \%$ of the observations made and several of the smaller cannula sizes (\#6-\#8) were similarly available. Larger-size cannula and adaptors were consistently available. These findings point out the need for the addition of several MVA instrument sets to resolve these problems.

While the instruments donated in 1996 are broken or worn out, the hospital received an additional MVA shipment from the Ministry of Health, according to the key informants interviewed. This shipment was likely the Ipas donation made to the hospital via the Ministry of Health at the end of the original project in early 1998. The department head has physical responsibility for the instruments and staff obstetrices manage the stock in the emergency unit, including replacement of worn or lost parts. Efforts are underway to add MVA to the purchase list for hospital supplies.

Respondents consistently reported that stock-outs of medications, other supplies and equipment for PAC services are rare. Apart from the MVA instrument, all other items necessary for PAC are utilized for other ob-gyn care, so that special purchases are unnecessary. The inventory identified several gaps in supplies and equipment, however. A complete emergency resuscitation kit was not consistently available; key elements (Mayo tube), for example, were only occasionally observed. Supplies for adequate infection prevention procedures were also lacking. Clean hand towels for staff, decontamination bucket, covered waste can, sharps disposal and cleaning gloves were found in less than $25 \%$ of the observations made. Linen for the procedure was only occasionally available and sanitary napkins were never available; the addition of both items would contribute to patient comfort.

Pain medications were in short supply in the emergency room, indicating that patients must purchase these items from the hospital or nearby commercial pharmacies. Our data 
indicated that the pain medications purchased are used almost exclusively for control of pain during the evacuation, rather than before or after the procedure. A small supply of pain medications kept for use during these periods could address this issue. Most types of contraceptive commodities were consistently found in the emergency room, although injectables were noted in only $59 \%$ of the observations. This gap may reflect the popularity of the method by postabortion patients and the need to ensure that requests by the staff obstetrices for resupply are made before stocks are depleted.

The inventory of support services found that admission personnel and infrastructure (signage, tariffs posted) were always available. Similarly, basic laboratory tests were routinely available, although no pregnancy tests were noted in any of the observations. Emergency room physicians often order ultrasounds for postabortion patients, although these services were only open in less than half the inventory visits. The blood bank was only open in $59 \%$ of observations, with only more common blood types available.

A major challenge faced by women seeking care and hospital staff is the lack of patients' resources to purchase necessary medications. The lack of funds sometimes causes delays in initiating clinical care and emergency room staff may resort to borrowing sample medications donated to the hospital or those designated for other clinical care. Women without sufficient resources who present with ob-gyn emergencies such as Caesarian deliveries have access to a "basket" of free or reduced cost medications. This is not the case for PAC patients and several respondents recommended the implementation of a medications "stock" for women with limited financial means. PAC patients are currently forced to purchase larger quantities of medications than actually needed for their care, due to standard packaging. A medications "stock" for PAC patients could size medications tailored to the clinical situation for postabortion treatment, reducing waste and lowering costs.

With respect to human resources, key informants reported that the emergency room had adequate personnel to meet the volume of PAC patients. The inventory confirmed that staff and student obstetrices were present at virtually all observation times in the emergency room, while residents were available during $3 / 4$ of the 17 visits.

The addition of the new emergency unit launched the improved PAC services in a positive direction. With a supportive physical infrastructure, sufficient stocks of supplies and equipment for most items, along with adequate personnel, the services have become well established and incorporated into mainstream ob-gyn emergency care. A focus on gaps identified through the inventory and interviews could further upgrade the quality of PAC services offered. 


\section{RECOMMENDATIONS}

The challenges for the hospital to maintain their PAC services lie in two areas. The first has to do with reinforcing those components of service delivery that have done well to date. The second is the need to strengthen those weak points that could benefit from sustained attention. This section outlines recommendations to meet these challenges.

While routines are necessary to ensure long-term sustainability, the energy and interest generated during the pilot project phase can suffer over time, particularly as new staff enter the service site. To ensure the continuation of positive outcomes such as the use of MVA, delivery of postabortion contraceptive information and methods and ambulatory organization of services, and improvements in those areas with deficits such as pain management, the hospital could focus on four activities.

Expanded communication about PAC services with the new leadership of the hospital. The current hospital director and other administrators have participated in the dissemination events and the study tour but could likely benefit from additional information on the status of services, benefits to patients and the hospital, and problems encountered.

Regular refresher training for all staff involved in PAC. Not only would training be a motivator for staff but such activities could reinforce high-quality practices and provide staff the skills to upgrade weaker areas. For example, the provision of general postabortion family planning information is strong, but patients could benefit from additional specifics about their method of choice.

Addition of selected essential supplies and equipment. The continued use of donated MVA kits has facilitated service sustainability, however, the addition of MVA instruments to the standard hospital purchase list is necessary to avert problems with deteriorated and eventually unusable instruments. The emergency room leadership should also examine the gaps identified in certain essential supplies and equipment, either through changes in procedures for re-supply or the addition of back-up stocks.

Development of written clinical protocols. Preparation of the protocols should be based on the latest scientific evidence and thoroughly and routinely reviewed with new and existing emergency room personnel. In particular, protocols for pain management could facilitate better and more individualized practices for alleviating women's discomfort throughout the treatment process. Difficulties in pain management are common to many, if not most, facilities offering PAC and changing ingrained clinical habits is quite challenging (Solo, 2000). Our study findings should provide a strong incentive to making progress at Hospital Carrión.

Establishment of guidelines for patient fees. The problems in the collection of patient fees occurred in a health care system with diminishing resources and increasing demands for care. These pressures are unlikely to be resolved in the short- or medium-term. However, the administrative process surrounding fee collection could certainly be 
improved so that guidelines for reduction of fees are clearer and more consistently applied, staff attitudes toward the process are more positive, postabortion patients are not singled out for excessive payments, women in the most serious economic circumstances do not encounter unnecessary barriers, clinical care is quickly provided and unnecessary hospitalizations are avoided. Many of these problems appear to be common across the hospital, so addressing these issues will likely take high-level action by the hospital administration, department heads and others.

The lessons learned from the long-term experience of Hospital Carrión can continue to benefit PAC services in Peru and the Latin American region. The findings of the original study are not well known within the country. The 1998 final dissemination workshop for the project was cancelled at the request of USAID/Peru due to controversies unrelated to PAC in the national family planning program at the time. The current study has offered an opportunity to inform key decision-makers about the nature of a sustainable, highquality PAC program. With minimal resource investment and strong political leadership, postabortion care can truly become accessible to women throughout Peru and the rest of Latin America. 


\section{REFERENCES}

Benson, J., \& Huapaya, V. (2002). Sustainability of postabortion care in Peru: Report of rapid assessment visits to four hospitals (Final report to the Frontiers Project). Chapel Hill, NC: Ipas.

Benson, J. (1998). Future directions in postabortion care research. In D. Huntington (Ed.), Advances and Challenges in Postabortion Care Operations Research, Summary Report of a Global Meeting. New York: The Population Council.

Benson, J., Huapaya, V., Abernathy, M., \& King, T. (1998). Improving quality and lowering costs in an integrated postabortion care model in Peru (Final report to the INOPAL Project). Carrboro, NC: Ipas.

Billings, D.L., Del Pozo, E., \& Arévalo, H. (2001). Testing a model for the delivery of postabortion care in the Bolivian public health system (Final report to the Frontiers Project). Mexico City: Ipas.

Bossert, T.J. (1990). Can they get along without us?: Sustainability of donor-supported health projects in Central America and Africa. Social Science and Medicine 30, 10151023.

Bratt, J.H., Foreit, J., \& de Vargas, T. (1998). Three strategies to promote sustainability of CEMOPLAF clinics in Ecuador. Studies in Family Planning 29, 58-68.

Díaz, J., Loayza, M., Torres de Yépez, Y., Lora, O., Alvarez, F., \& Camacho, V. (1999). Improving the quality of services and contraceptive acceptance in the postabortion period in three public-sector hospitals in Bolivia. In D. Huntington and N.J. Piet-Pelon (Eds.), Postabortion Care, Lessons Learned from Operations Research. New York: The Population Council.

Engender Health \& Ipas. (2001). Taking postabortion care services to scale: Quality, access, sustainability, report of an international workshop held in Mombasa, Kenya, May 15-18, 2000. New York: Author.

Farfán, O., Kestler, E., Abrego de Aguilar, M.M., Jarquín, D., Vallecillos, G., Pérez, L., et al. (1997). Información y consejería en planificación familiar post-aborto. Experiencia en cuatro hospitales de Centro América. Revista Centroamericana de Ginecología y Obstetricia 7, 45-56.

Greenslade, F.C., McKay, H., Wolf, M., \& McLaurin, K. (1994). Postabortion care: A women's health initiative to combat unsafe abortion. Advances in Abortion care 4, 1-4. Carrboro, NC: Ipas.

Greenslade, F.C., Leonard, A.H., Benson, J., Winkler, J., \& Henderson, V.L. (1993). Manual vacuum aspiration: A summary of clinical and programmatic experience worldwide. Carrboro, NC: Ipas. 
Huntington, D., Ezzeldin, O.H., Attalla, N., Toubia, N., Naguib, M., \& Nawar, L. (1995). Improving the medical care and counseling of postabortion patient in Egypt. Studies in Family Planning 26, 350-362.

Instituto Nacional de Estadística e Informática, Measure/DHS+, Macro Internacional, Inc., USAID, \& UNICEF. (2001). Encuesta demográfica y de salud familiar 2000. Lima, Peru: Instituto Nacional de Estadística e Informática.

Johnson, B.R., Ndhlovu, S., Farr, S., \& Chipato, T. (2002). Reducing unplanned pregnancy and abortion in Zimbabwe through postabortion contraception. Studies in Family Planning 33, forthcoming.

Langer, A., García-Barros, C., Heimburger, A., Stein, K., Winikoff, B., \& Barahona, V. (1999). Improving postabortion care with limited resources in a public hospital in Oaxaca, Mexico. In D. Huntington and N.J. Piet-Pelon (Eds.), Postabortion Care, Lessons Learned from Operations Research. New York: The Population Council.

Latin American and Caribbean Committee for the Defense of Women's Rights (CLADEM), The Center for Reproductive Law and Policy (CRLP), \& DEMUS, Estudio para le Defensa de los Derechos de la Mujer. (1998). Women's sexual and reproductive rights in Peru: A shadow report. Lima, Peru: Author.

Shepperd, J.D. (1991). Capacity building for the health sector in Africa. Asia-Pacific Journal of Public Health 5, 131-144.

Singh, S. \& Wulf, D. (1994). Estimated levels of induced abortion in six Latin American countries. International Family Planning Perspectives 20, 4-13.

Solo, J. (2000). Easing the pain: Pain management in the treatment of incomplete abortion. Reproductive Health Matters 8, 45-51.

Solo, J., Billings, D.L., Aloo-Obunga, C., Ominde, A., \& Makumi, M. (1999). Creating linkages between incomplete abortion treatment and family planning services in Kenya. Studies in Family Planning 30, 17-27.

Távara Orozco, L. \& Ramírez Jiménez, Y. (1996). Atención del aborto incompleto no complicado. Lima: INPPARES, IPPF and the Bergstrom Foundation. 


\section{Annex 1. Model of Sustainability of Postabortion Care (PAC) in Peru}

Original Study Stage 1 (1996)

Assessment of Pre-

Intervention PAC Services

\begin{tabular}{|c|}
\hline $\begin{array}{c}\text { Clinical } \\
\text { technique }\end{array}$ \\
\hline $\begin{array}{c}\text { Provision of } \\
\text { postabortion } \\
\text { family } \\
\text { planning } \\
\text { information }\end{array}$ \\
\hline $\begin{array}{c}\text { Provision of } \\
\text { contraceptive } \\
\text { methods }\end{array}$ \\
\hline $\begin{array}{c}\text { Provision of } \\
\text { medical } \\
\text { information to } \\
\text { patients }\end{array}$ \\
\hline $\begin{array}{c}\text { Cost and } \\
\text { length of } \\
\text { patient stay }\end{array}$ \\
\hline
\end{tabular}

Original Study

Stage 2 (1997)

Assessment of Post-

Intervention PAC

Services

Components of
PAC Intervention
--Provider
training
--Improved
clinical care
(e.g., use of
MVA)
--Postabortion
family planning
counseling/
services
--Medical
information/
counseling
--Re-
organization of
services (e.g.,
from inpatient to
outpatient)

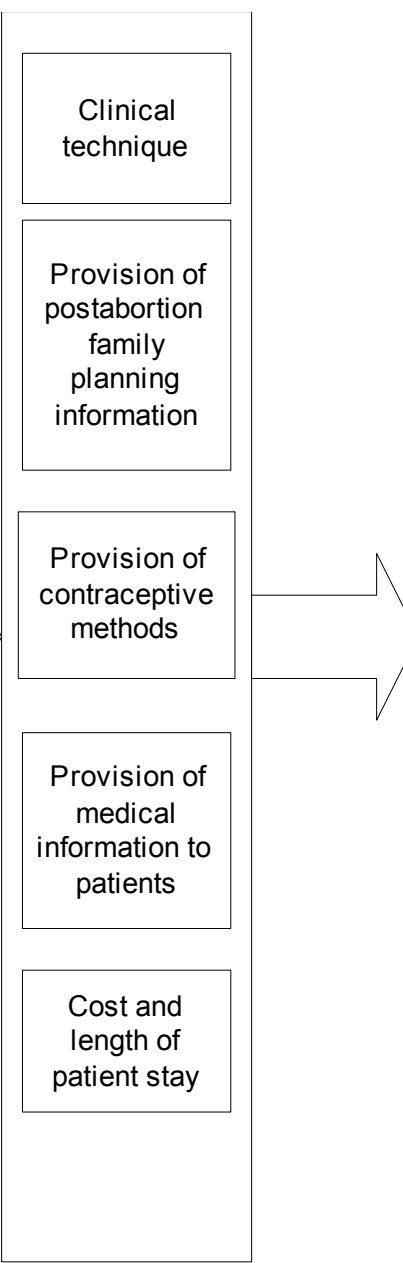

Present Study Stage 3 (2000-01)

Assessment of Follow up PAC Services

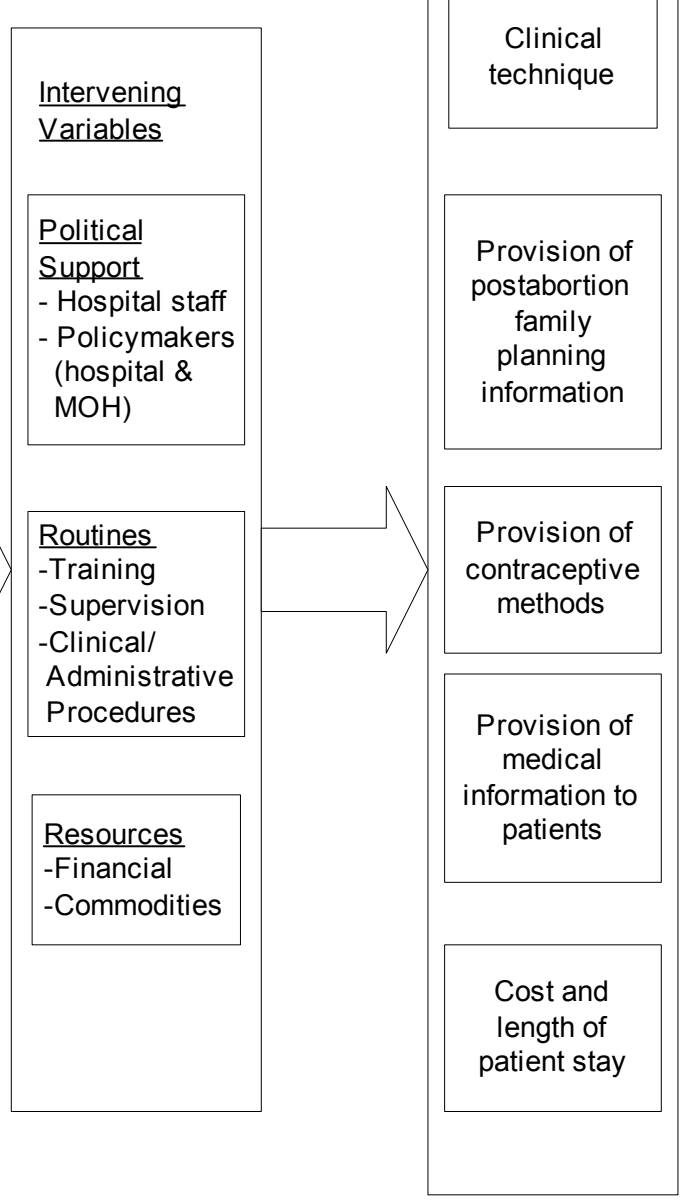

